\title{
Isolation and characterization of a mutant defective in triacylglycerol accumulation in nitrogen-starved Chlamydomonasreinhardtii
}

\author{
Chun-Hsien Hung ${ }^{1}$, Kazue Kanehara ${ }^{1}$, and Yuki Nakamura ${ }^{1,2^{\star}}$
}

${ }^{1}$ Institute of Plant and Microbial Biology, Academia Sinica, $128 \mathrm{sec} .2$ Academia Rd. Nankang, Taipei 11529, Taiwan.

${ }^{2}$ PRESTO, Japan Science and Technology Agency, A-1-8 Honcho Kawaguchi, Saitama, Japan.

"Corresponding author: Yuki Nakamura, Institute of Plant and Microbial Biology, Academia Sinica, 128 sec.2 Academia Rd., Nankang, Taipei 11529, Taiwan. Email:nakamura@gate.sinica.edu.tw

Chun-Hsien Hung, E-mail: sunnyyaung@gate.sinica.edu.tw

Kazue Kanehara, E-mail: kanehara@gate.sinica.edu.tw 
Keywords:Triacylglycerol, Glycerolipid metabolism, Nitrogen starvation, Metabolomics, Chlamydomonasreinhardtii.

Abbreviations: G6P,glucose 6-phosphate;G1P, glucose 1-phosphate; F6P, fructose 6-phosphate;F16BP, fructose 1,6bisphosphate;GA3P,glyceraldehyde3-phosphate;3-PGA, 3-phosphoglycerate; DHAP, dihydroxyacetone phosphate;PEP, phosphoenolpyruvate; G3P, glycerol 3-phosphate; LysoPA, lysophosphatidic acid; PA, phosphatidic acid; DAG, sn1,2-diacylglycerol; TAG, triacylglycerol. 


\section{ABSTRACT}

Triacylglycerol (TAG), a major source of biodiesel production, accumulates innitrogen-starvedChlamydomonasreinhardtii. However,the metabolic pathwayof starch-to-TAG conversion remains elusive because an enzyme that affects the starch degradation is unknown. Here, we isolated a new class of mutantbgal1, which expressed an overaccumulation of starch granules and defective photosynthetic growth. The bgal1was a null mutantof a previously uncharacterized $\beta$-galactosidase-like gene (Cre02.g119700), which decreased total $\beta$-galactosidase activity $40 \%$ of wild type.Upon nitrogen starvation, the bgal1mutant showed decreased TAG accumulation mainly due to the reduced flux of de novo TAG biosynthesis evidenced by increasedunsaturation of fatty acid composition in TAG and reduced TAGaccumulation byadditional supplementation of acetate to the culture media. Metabolomic analysis of the bgal1 mutant showed significantly reduced levels of metabolites following the hydrolysis of starchand substrates for TAG accumulation, whereas metabolites in TCA cycle were unaffected. Upon nitrogen starvation, while levels of glucose 6-phosphate, fluctose 6-phosphate and acetyl-CoA remained lower, most of the other metabolites in glycolysis were increased but those in the TCA cycle were decreased, supporting TAG accumulation.We suggest that BGAL1 may be involved in the degradation of starch, which affects TAG accumulation in nitrogen-starvedC. reinhardtii. 


\section{Introduction}

Eukaryotic algae have been focused as bioresource of biodiesel creation because of their high capacity of lipid accumulation and little conflict with land plant cultivation. A primary source of biodiesel is represented by triacylglycerol (TAG), which has three acyl chains bound to the glycerol backbone serving as storage of carbon source and energy.

Chlamydomonasreinhardtii is an established model of eukaryotic microalga. Under nutrient deficiency, C. reinhardtii triggers accumulation of TAG at the expense of active cell growth. Among different nutrient starvation tested, including nitrogen $(\mathrm{N})$, phosphorus $(\mathrm{P})$, sulfur $(\mathrm{S})$, iron $(\mathrm{Fe})$ and zinc $(\mathrm{Zn})$ starvation, $\mathrm{N}$ starvation best triggers the increase in TAG (Matthew et al., 2009; Kropat et al., 2011; Breuer et al., 2012; Cakmak et al., 2012; Msanne et al., 2012). Based on the current model in C. reinhardtii and related species, TAG accumulation occurs at the ER, plastids, and the contact site between plastids and the ER (Fan et al., 2011; Goodson et al., 2011). The final step of TAG biosynthesis is catalyzed by diacylglycerol acyltransferase (DGAT) which transfers an acyl group to sn-1,2-diacylglycerol (DAG). Chlamydomonas has at least two types of DGAT that take acyl-CoA as acyl donor; type I consists of DGAT1 and type II consists of DGTT1, 2, 3, 4 and 5(Boyle et al., 2012; Msanne et al., 2012; Hung et al., 2013; Sanjaya et al., 2013). Moreover, another type of acyltransferase, phospholipid:diacylglycerol acyltransferase1 (PDAT1), transfers acyl groups from wide range of glycerolipids to TAG (Yoon et al., 2012). Recently, monogalactosyldiacylglycerol (MGDG), a signature lipid class of photosynthetic membranes, was shown as a plastidic source of certain acyl 
groups in TAG biosynthesis (Li et al., 2012). A mutation in MGDG lipase, PGD1, that hydrolyzes acyl moiety of MGDG to lyso MGDG, affects TAG accumulation following $\mathrm{N}$ starvation. The liberated fatty acid is used for TAG production.

The primary pathway of photo-assimilated carbon source to TAG is complex and not clearly understood yet. However, gene knock out study in $C$. reinhardtii provides numerous information. For example, starchless6 (sta6) mutant, which is defective in small subunit of ADP-Glcpyrophosphorylase, affects starch biosynthesis and hence accumulates large amount of TAG upon $\mathrm{N}$ starvation (Mouille et al., 1996). This is considered due to the blockage of carbon flux to storage carbohydrate (Ramazanov and Ramazanov, 2006; Wang et al., 2009; Li et al., 2010b; Li et al., 2010a; Work et al., 2010; Fan et al., 2011; Sanjaya et al., 2011). Indeed, comparative time-course transcriptomics of thesta6mutant suggested that glyoxylate pathway and gluconeogenesis are upregulated to promote carbon flux toward hexose-phosphate (Blaby et al., 2013). Thus, metabolomics study using gene knockout models provides ample evidence on the metabolism of primary carbon-containing compounds in $C$. reinhardtii. Because of the limited number of mutants in $C$. reinhardtii affecting TAG biosynthesis, however, we are in need of more gene knock out models with altered TAG profiles to investigate mechanism of TAG accumulation in vivo.

Here, we report a new class of mutant bgal1, which was isolated while screening transgenic mutants of $C$. reinhardtii which expresses an artificial microRNA designed to target a putative MONOGALACTOSYLDIACYLGLYCEROL1 (CrMGD1; Cre13.g585301). The 
bgal1 did not suppress CrMGD1 but showed decreased TAG accumulation under $\mathrm{N}$ starvation. It showed significantly impaired photosynthetic growth and over-accumulation of starch granules under N-replete condition, showing the phenotype opposite to that of thesta6. The bgal1 mutant has an insertional mutation in the open reading frame of $B G A L 1$, a previously uncharacterized $\beta$ galactosidase-like gene. Cell biological and metabolomic analyses showed that BGAL1 may be involved in the hydrolysis of starch. We suggest that BGAL1 may be involved in the key step of starch degradation, which affects TAG accumulation under nitrogen-starvedC. reinhardtii.

\section{Materials and methods}

\subsection{Culture condition}

$$
\text { C.reinhardtiistrain was obtained from }
$$
ChlamydomonasResource Center (St. Paul, MN) and used as a wild type.Cells were grown in Tris-acetate-phosphate (TAP) medium (Gorman and Levine, 1965)or high salt (HS) medium (Sueoka, 1960)supplemented with $50 \mathrm{mg} \mathrm{L}^{-1}$ of arginine with air bubbling under $50 \sim 60 \mu \mathrm{mol}$ continuous white light at $22^{\circ} \mathrm{C}$ by stirringat 200rpm. C. reinhardtii strain CC-4351 transformed with empty pChlamiRNA2 plasmid(Molnar et al., 2009) was used as empty vector control strain (Hung et al., 2015). Cell numberwas counted by automatic cell counter (Cellometer ${ }^{\circledR}$ AutoT4, Nexcelom Bioscience, Lawrence, MA). For measurement of TAG content under $\mathrm{N}$ starvation condition, cells grown in $250 \mathrm{~mL}$ TAP medium to the cell density of $\sim 6 \times 10^{6} \mathrm{~mL}^{-1}$ werewashedtwice with $250 \mathrm{~mL}$ TAP (-N) medium by centrifugation. The cell pellets were suspended in TAP (-N) medium by adjusting the cell density to $3 \times 10^{6} \mathrm{~mL}^{-1}$ for $\mathrm{N}$-starved growth. For 
acetate boosting, cell pellets were suspended in TAP $(-\mathrm{N})$ supplemented with $20 \mathrm{mM}$ potassium acetate as previously described (Goodson et al., 2011). The strains used are listed in Table S1.

\subsection{Plasmid constructs and transformation}

The 90-mer oligonucleotides for artificial miRNAdesigned to target a putative CrMGD1 specifically (YN1253 and YN1254) were annealed and ligated into the Spel site of the pChlamiRNA2 to produce pKK501. The plasmids pChlamiRNA2 and pKK501 were linearized by digesting with HindIII and transformed into strain CC-4351 using glass beads as described (Kindle, 1990; Molnar et al., 2009). Control (CHC041) and thebgal1(CHC042)mutant were screenedonsolid TAP media with $2 \%$ agar.The primers and plasmids used are listed in Table S2 and Table S3, respectively.

\subsection{Isolation of the bgal1 mutant}

Genomic DNA of CC-4351 and transgenic strains was extractedfrom exponentially growing cells by lysis buffer (1\% SDS, 200 mMNaCl, 40 mMTris$\mathrm{HCl} \mathrm{pH}$ 8.0, $20 \mathrm{mM}$ EDTA)and phenol(Newman et al., 1990). The flanking sequences of transgene insertion position were determined by thermal asymmetric interlaced (TAIL)-PCR as described in (Dent et al., 2005) with 3 specific and 4 arbitrary degenerate primers for primary, secondary, and tertiary reactions.Sequences of the primers are listed in Table S4.

\subsection{Genotype analysis and prediction of chloroplast transit} peptidesGenomic DNA was isolated from cells of the wild type and thebgal1 mutant.The primers $\mathrm{CH} 428$ and $\mathrm{CH} 456$ were designed to amplify a 616-bp 
fragment from the wild type genetic background, and primers $\mathrm{CH} 455$ (specific to pChlamiRNA2) and $\mathrm{CH} 456$ (specific to BGAL1) were used to amplify a $602-$ bp fragment from the bgal1 mutant. The putative chloroplast transit peptides

were predicted by ChloroP 1.1 Server (http://www.cbs.dtu.dk/services/ChloroP/) (Emanuelsson et al., 2000).

\subsection{RNA extraction and $q R T-P C R$ analysis}

Total RNA was extracted by use of TRI reagent (Ambion) including DNase treatment and reverse-transcribed with SuperScript III (Invitrogen, Carlsbad, CA) for cDNA synthesis. Quantitative RT-PCR involved the ABI 7500 Real Time PCR System (Applied Biosystems) with the oligonucleotide primers for ACT1 (Cre13.g603700; CH577 and CH578), MGD1 (Cre13.g585301; CH890 and CH891) and BGAL1(Cre02.g119700; CH964 and CH965). Gene expression was normalized to that of ACT1 (Cre13.g603700). Data were averaged by 3 technical replicates in the same run and 3 biological replicates in separate runs.

\subsection{Quantification of chlorophyll contents}

Chlorophyll contents were analyzed as described (Arnon et al., 1954).Briefly, C.reinhardtiicells were grown in TAP or TAP (-N) media andharvested by centrifugation. Chlorophyll was extracted by $80 \%$ acetone with vigorous vortex and centrifugation, and the supernatant was separated to measure absorption at $645 \mathrm{~nm}$ and $663 \mathrm{~nm}$. 


\subsection{Measurement of oxygen evolution}

Oxygen evolution was measured with a Clark type oxygen electrode (YSI model 5331 oxygen probe) fitted with a water-jacketed cell as described previously (Hung et al., 2007).

\subsection{Quantification of starch contents}

Starch contents were analyzed as previously reported (Doebbe et al., 2010) using an assay kit (Cat. No. 10-207-748-035, Roche). Cells were cultured in N-replete condition to a density of $\sim 3 \times 10^{6}$ cells $\mathrm{mL}^{-1}$ before transferring to $\mathrm{N}$-starved condition to a final cell density of $2 \times 10^{6}$ cells $\mathrm{mL}^{-1}$. Samples were taken at the time of transferring to $\mathrm{N}$-starved condition ( 0 day), 1 day, and 5 days after the transfer.

\subsection{Lipid extraction and analysis}

C. reinhardtiicells were grown in TAP medium at $22^{\circ} \mathrm{C}$ and harvested by centrifugation. Cell pellets were treated with pre-heated isopropanol containing $0.01 \%$ butylated hydroxytoulene at $75{ }^{\circ} \mathrm{C}$ for $15 \mathrm{~min}$ to inactivate phospholipase activity. Total lipids were extracted as described (Folch et al., 1957). Neutral lipids were separated from total lipid extracts by onedimensional thin-layer chromatography (TLC) (Silica Gel 60 F254 plate, Merck) with the solvent system of hexane:diethylether:glacial acetic acid (40:10:1, v/v/v) and visualized by primuline staining. Lipid analysis was conducted as described (Nakamura et al., 2003). Fatty acid methyl esters derived from TAG were analyzed by gas chromatography (GC-2010; Shimadzu, Kyoto, Japan) equipped with a ULBON HR-SS-10 column (Shinwa Chemical Industries, Kyoto, Japan). 


\subsection{Transmission electron microscopic (TEM) observation}

C. reinhardtiiwild type control and bgal1cells were grown to a density of $\sim 3 \times 10^{6} \mathrm{~mL}^{-1}$ in TAP medium at $22^{\circ} \mathrm{C}$. $\mathrm{N}$ deficiency was induced by collecting the cells by centrifugation ( 5 min at $3,000 \times g$ ), washing twice with the TAP medium without $N\left(\right.$ TAP-N) and subsequently adjusting cell density to $2 \times 10^{6}$ $\mathrm{mL}^{-1}$ in TAP-N media. Samples were taken at 1 day after the transfer to TAP-N media. Samples at day 0 were taken before transferring to $\mathrm{N}$-starved condition.For TEM observation, samples were frozen using high pressure freezer EMPACT2 (Leica, Vienna, Austria) at pressure of 2,000-2,050bar. Freeze substitution was performed in anhydrous acetone (containing $1 \% \mathrm{OsO}_{4}$ and $0.1 \%$ UA) usingLeica EM AFS2 (automatic freeze substitution). The samples were kept at $-80^{\circ} \mathrm{C}$ for 3 days, then at $-60^{\circ} \mathrm{C},-20^{\circ} \mathrm{C}$ and $0^{\circ} \mathrm{C}$ for 1 day each, thenmoved to the room temperature. After twice rinsing for 12 hours with acetone, the LR White resin was used for infiltration and embedding. Ultrathin sections (70-90nm) were obtained using a Reichert Ultracut S or Lecia EM UC7 (Leica, Vienna, Austria) and collected using 100 mesh copper grids. The sections were stained with $5 \%$ uranyl acetate in $50 \%$ methanol for 10 min and 0.4\% lead citrate for 4-6 min. Sections were observed using a TEM (CM 100, Philips) at $80 \mathrm{KV}$ and the images were taken with GatanOrius CCD camera.

\subsection{1. $\beta$-galactosidase activity assay}

C. reinhardtiiwild type control and the bgal1cells were grown to a density of $1 \sim 4 \times 10^{6} \mathrm{~mL}^{-1}$ in TAP medium at $22^{\circ} \mathrm{C}$. Fifteen milliliter of culture was harvested by centrifugation $\left(3,000 \times g, 5 \mathrm{~min}\right.$ at $\left.4^{\circ} \mathrm{C}\right)$. Cells were disrupted by 
vortexing twice for $30 \mathrm{sec}$ with $0.5 \mathrm{~mL}$ Zirconia/Silica beads (BioSpec, Cat.11079105z) and $0.8 \mathrm{~mL}$ of lysis buffer (100 mM sorbitol, $50 \mathrm{mM}$ potassium acetate, 20 mMTris- $\mathrm{HCl}, \quad \mathrm{pH} \quad 7.5, \quad 0.5 \quad$ mMdithiothreitol, $1 \mathrm{mMphenylmethylsulfonyl} \mathrm{fluoride).} \mathrm{Theprotein} \mathrm{concentration} \mathrm{of} \mathrm{the}$ supernatant of cell lysate was measured by BCA Protein Assay Kit (Pierce, Thermo Scientific) andthe $\beta$-galactosidase activity was assayed using $\beta$ Galactosidase Assay Kit (Agilent Technologies) with O-Nitrophenyl- $\beta$-DGalactopyranoside (ONPG) as the substrate.The $\beta$-galactosidase activity was expressed in units/mg of lysate(Nielsen et al., 1983).Data were averaged by 3 biological replicates with SD.

\subsection{Sample preparation for metabolomics analysis}

C. reinhardtii wild type control and the bgal1 cells were grown to a density of $\sim 3 \times 10^{6} \mathrm{~mL}^{-1}$ in TAP medium at $22{ }^{\circ} \mathrm{C}$ with the light intensity of $50-60$ $\mu \mathrm{mol}$ photons $\mathrm{m}^{-2} \mathrm{~s}^{-1}$. N deficiency was induced by collecting the cells by centrifugation (5 $\mathrm{min}$ at $3,000 \mathrm{xg}$ ), washing twice with the TAP medium without $\mathrm{N}$ (TAP-N) and subsequently adjusting cell density to $2 \times 10^{6} \mathrm{~mL}^{-1}$ in TAP-N media. Cells were growth for 5 days then harvested by centrifugation $(3,000 x g$ for $5 \mathrm{~min}, 4^{\circ} \mathrm{C}$ ). The supernatant was removed and the wet cell weight was measured. Samples were frozen by liquid nitrogen and kept under $-80{ }^{\circ} \mathrm{C}$ till use. Based on the wet weight measured, an internal standard D-fructose- $\left[{ }^{13} \mathrm{C}_{6}\right]$ 1,6-bisphosphate sodium salt hydrate (Cat. No. F792571, Toronto Research Chemicals, Ontario, Canada) was added to the final concentration of $0.96 \mathrm{mM}$. Ice-cooled extraction solvent $\left(3.75 \mathrm{ml}\right.$ of $\mathrm{dH}_{2} \mathrm{O}, 7.5 \mathrm{ml}$ of methanol, $3.75 \mathrm{ml}$ of chloroform and $3 \mathrm{~mL}$ of $0.5 \mathrm{~mm}$ Zirconia/Silica beads) was added to $\sim 3 \mathrm{~g}$ of 
sample and cells were disrupted by vigorous vortex for $30 \mathrm{sec}$ for 3 times. Supernatant was separated by quick spin-down at $3,000 \mathrm{xg}$, incubated at $-30{ }^{\circ} \mathrm{C}$ for $30 \mathrm{~min}$, then centrifugated at $3,000 \times \mathrm{g}$ for $10 \mathrm{~min}$ at $4{ }^{\circ} \mathrm{C}$. Obtained supernatant was mixed by vortexing with $3.75 \mathrm{ml}$ of chloroformto remove pigments. Colorless supernatant was lyophilized and kept under $-80{ }^{\circ} \mathrm{C}$ for mass spectrometry assay. The lyophilized samples were dissolved in $10 \mathrm{mM}$ ammonium formate, $\mathrm{pH} 3.0$, and centrifuged at $15,000 \times \mathrm{xg}$ at $4{ }^{\circ} \mathrm{C}$ for $20 \mathrm{~min}$. The supernatant was transferred to a sample vial for metabolites analysis.

\subsection{Metabolite analysis}

Amount of fructose 1,6-biphosphate (F16BP), dihydroxyacetone phosphate (DHAP), 3-phosphoglycerate (3-PGA), phosphoenolpyruvate (PEP), glyceraldehyde 3-phosphate (GA3P), acetyl-CoA, citrate, aconitic acid, isocitrate, succinate, malate and ATP were analyzed by lon-Pair Chromatography (LCQ Deca XP Plus, ThermoFinnigan, San Jose, CA). LCQ mass spectrometry was performed with Agilent 1200 series binary HPLC system (Agilent Technologies, Palo Alto, CA) coupled to a LCQ Deca XP+ ion trap (Thermo Scientific) equipped with an electrospray ionization interface. The mass spectrometry was set to one full MS scan (m/z 50 to 850). Chromatographic separation was performed by passing aliquots through Agilent ZORBAX Eclipse XDB-C8 $2.1 \times 12.5 \mathrm{~mm}$ pre-column (Agilent Technologies), before separation with a column (ZORBAX Eclipse XDB-C18, $2.1 \times 150 \mathrm{~mm}, 5 \mu \mathrm{m}$; Agilent) at room temperature using a multistep gradient with online-degassed eluent $A$ (10 mM tributylamine aqueous solution, adjusted 
to $\mathrm{pH} 5$ with $15 \mathrm{mM}$ acetic acid and $2 \%$ methanol): 0 to $5 \mathrm{~min}, 99.9 \%$ to $95 \% \mathrm{~A}$; 5 to $25 \mathrm{~min}, 95 \%$ to $73 \% \mathrm{~A} ; 25$ to $30 \mathrm{~min}, 73 \%$ to $68 \% \mathrm{~A} ; 30$ to $35 \mathrm{~min}, 68 \%$ to $1 \% \mathrm{~A} ; 35$ to $36 \mathrm{~min}, 1 \%$ to $1 \% \mathrm{~A} ; 36$ to $37 \mathrm{~min}, 1 \%$ to $99.9 \% \mathrm{~A}$. The flow rate was $0.5 \mathrm{~mL}^{-1} \mathrm{~min}^{-1}$. The volume of injected sample was $10 \mu \mathrm{l}$. After separation, compounds were ionized by electrospray ionization and detected by the LCQ that was operated in negative ion mode with the spray voltage of $4.5 \mathrm{kV}$, sheath gas at $30(a r b)$ and capillary temperature at $300^{\circ} \mathrm{C}$. Prior to injection, a mixture of $25 \mathrm{ppm}$ (final concentration) of reference compounds and $166.6 \mathrm{ppm}$ of $\mathrm{D}$ fructose $-{ }^{13} \mathrm{C}_{6} 1,6$-Bisphosphate was added to the sample to correct matrix effects on these analytes in the analysis. The mass spectrometry data were analyzed using software Xcalibur 2.2 (Thermo Scientific).

Amount of glucose 6-phosphate (G6P), glucose 1-phosphate (G1P) and fructose 6-phosphate (F6P) were analyzed with ACQUITY UPLC system (Waters, Manchester, UK) equipped with ACQUITY UPLC BEH amide column $(130 \AA, 1.7 \mu \mathrm{m}, 2.1 \mathrm{~mm} \times 100 \mathrm{~mm})$. The column temperature was set at $25^{\circ} \mathrm{C}$. The UPLC mobile phase consisted of $40 \%$ acetonitrile/10mM ammonium acetate, pH9.0 (solution A) and $95 \%$ of acetonitrile/10mM ammonium acetate, pH9.0 (solution B). The linear gradient increased: 0 to $1 \mathrm{~min}, 35 \%$ to $35 \% \mathrm{~A} ; 1$ to $5 \mathrm{~min}, 35 \%$ to $55 \% \mathrm{~A} ; 5$ to $5.01 \mathrm{~min}, 55 \%$ to $35 \% \mathrm{~A} ; 5.01$ to $9 \mathrm{~min}, 35 \%$ to $35 \% \mathrm{~A}$. The injection volume was $1.0 \mu \mathrm{l}$. The mass spectrometric data were collected by a SYNAPT ${ }^{\mathrm{TM}}$ High Definition Mass Spectrometry ${ }^{\mathrm{TM}}$ G1 (Synapt HDMS $^{\mathrm{TM}}$ G1) System (Waters, Manchester, UK) with an electrospray ionization (ESI) interface, ion-mobility and time-of-flight system. An electrospray source was used; sample cone voltage of $40 \mathrm{~V}$ capillary was set at $2.5 \mathrm{kV}$, the source 
and desolvation temperatures were $80^{\circ} \mathrm{C}$ and $250{ }^{\circ} \mathrm{C}$, respectively, and the desolvation and cone gas flow rates were $800 \mathrm{~L} \mathrm{~h}^{-1}$ and $50 \mathrm{~L} \mathrm{~h}^{-1}$, respectively. Spectra were collected in the negative ionization (ES-). A lock mass calibration of sulfadimethoxin at a concentration of $0.05 \mathrm{mg} / \mathrm{L}$ in water/MeOH $(50: 50, \mathrm{v} / \mathrm{v})$ was introduced by HPLC pump (LC-10ATVP, Shimadzu, Japan) and split the $20 \mu \mathrm{l} / \mathrm{min}$ to lock spray interface. The MS range acquired was $50-1000 \mathrm{~m} / \mathrm{z}$ with $0.2 \mathrm{sec} / \mathrm{scan}$ in centroid mode. Prior to injection, a mixture of $100 \mathrm{ppm}$ (final concentration) of reference compounds and $100 \mathrm{ppm}$ of D-fructose- ${ }^{13} \mathrm{C}_{6}$ 1,6-Bisphosphate were added to the sample to correct matrix effects on these analytes in the analysis. The mass data acquired were imported to Markerlynx (Waters, Manchester, UK) within Masslynx and Targetlynx software (version 4.1) for peak detection and alignment. The retention time and $\mathrm{m} / \mathrm{z}$ data for each peak were manually determined.

\section{Results}

\subsection{Isolation of amutantthat exhibits defective photosynthetic growth in C.reinhardtii}

While screening transgenic mutants of C.reinhardtii which expresses an artificial microRNA designed to target a putative MONOGALACTOSYLDIACYLGLYCEROL1 (CrMGD1; Cre13.g585301), we found a transformant showing pale green color and defective growth (Figure 1A). The pale green phenotype persisted after several generations. However, thismutant (bgal1, as designated in Figure 2) did not suppress levels ofMGD1 transcript compared with the wild type strain (CC-4351) (Figure 1B). Thissuggests that the phenotype is caused not by suppression of the 
putativeMGD1 butan insertion of a transgene into the genome of $C$. reinhardtii, where a functional gene that accounts for this phenotype is encoded. Chlorophyll contents of the bgal1were about a half as compared to that of wild type under the photoheterotrophic condition (Figure 1C). Under photoheterotrophic condition (TAP media), the growth of thebgal1mutant was considerably slower as compared to wild type, which resulted in cell number about 4 times lower than that of wild type in 3 days (Figure 1D). The phenotype was more pronounced under photoautotrophic condition (HS media), where cell growth of thebgal1mutant was almost stopped (Figure 1E). We measured oxygen evolution of the bgal1 mutant as a parameter of photosynthetic activity, which showed significant reduction compared to that of the wild type (Figure $1 \mathrm{~F})$. Thus, the bgal1mutant carried a mutation affecting photosynthetic growth that was not complemented by exogenously supplied carbon source in the culture media.

\subsection{A $\beta$-galactosidase-like gene was disrupted in thebgal1 mutant}

To identify the position of transgene insertion in the genome, we performed TAIL PCR and found the insertion within the open reading frame of a previously uncharacterized gene Cre02.g119700, which containsa putative $\beta$ galactosidase-like motif (Figure 2A).We designated this gene $\beta$-galactosidaselike1 (BGAL1). PCR-based genotyping confirmed that thebgal1 was homozygous (Figure S1A). Moreover, BGAL1 transcriptswere undetectable in thebgal1 mutant by qPCR (Figure 2B), indicating that bgal1 is a null mutant of BGAL1. Global BLAST search revealed thatBGAL1 is highly unique inmicroalgae, as proteins sharing overall high homology can be found in Volvox, 
Chlorella and Trichodesmium (see Figure S2 for phylogenetic relationship among them). Motif search by Pfam database revealed that a region ranging from amino acid residues 115 to 312 shares homology with glycosyl hydrolase 42 (GH42) superfamily represented by bgaB, a $\beta$-galactosidase of Baccilussabtilis(Figure $\mathrm{S} 1 \mathrm{~B}$ ). The ChloroP 1.1 program predicted thatNterminal amino acid residues 1-75 of BGAL1contains a possible chloroplast transit peptide (Figure S1B). To investigate whether BGAL1 is responsible for the major $\beta$-galactosidase activity, we performed enzyme activity assay using total crude protein extract from the bgal1 mutant. As compared to the wild type, $\beta$-galactosidase activity was reduced by $40 \%$ in thebgal1 mutant (Figure 2C). Taken together, these results indicate that thebgal1 is a knockout mutant of BGAL1 (Cre02.g119700), which is responsible for the primary $\beta$-galactosidase activity in $C$. reinhardtii.

\subsection{Observation of cell ultrastructure in thebgal1mutant}

Reduced $\beta$-galactosidase activity in thebgal1 mutant (Figure 2C) suggests an accumulation of carbohydrate, which may have relevance to the growth defect (Figure1). To investigate the defect in thebgal1 at cellular level, we observed the ultrastructure of thebgal1mutant cells by transmission electron microscope. A remarkable difference between thebgal1and wild type was the accumulation of starch granules within the chloroplasts:As compared with wild type (Figure 2D), massive accumulation of starch was observedin the bgal1 mutant (Figure 2E). A closer look at the organelle structure showed that thylakoid membranes as well as other sub-organelle compartment of chloroplasts be indistinguishable between wild type (Figure 2F)and 
thebgal1(Figure 2G). This observation suggests that defective photosynthetic growth observed in thebgal1 is likely caused by over-accumulation of starch.

\section{4. $\mathrm{N}$ starvation compromised growth defect of thebgal1mutant}

Over-accumulation of starch granules suggests that carbon flux is affected in the bgal1. Because TAG serves as an alternative fate of photoassimilated carbon source (Msanne et al., 2012; Blaby et al., 2013; Wang et al., 2015), we next observed the phenotype of thebgal1 under $\mathrm{N}$ starvation.

We performed time-course observation of cell growth in response to $\mathrm{N}$ starvation. Upon entry into $\mathrm{N}$ deprivation, wild type cells nearly stopped their growth. Both thebgal1 and wild type showed degradation of chlorophyll as evidenced by the changes in the green pigment color of culture (Figure 3A). We found that cell number was not significantly different between the bgal1 and wild typeuntil 7 days after switching to $\mathrm{N}$ starvation (Figure $3 \mathrm{~B}$ ), indicating that thedifference in growth phenotype betweenbgal1mutant and wild typewas less obvious under $\mathrm{N}$ starvation than under $\mathrm{N}$-replete condition. Interestingly, the degradation of chlorophyll contents occurred more rapidly in wild type than thebgal1, so thedifference in chlorophyll contentsbetween wild type and the bgal1became indistinguishable by 3 days after $\mathrm{N}$ starvation (Figure $3 \mathrm{C}$ ). Thus, the difference in growth phenotype ofbga/1mutant and wild type was less obvious under $\mathrm{N}$ starvation.

\subsection{Observation of cell ultrastructure in N-starved bgal1mutant}

To investigateaccumulation of starch granules andlipid droplets in $\mathrm{N}$ starved bgal1 mutant, we performed time-course observationof cell ultrastructure following $\mathrm{N}$ starvation by transmission electron 
microscopy.Before switching to $\mathrm{N}$-starved condition,compared to the wild type cell (Figure 4A), much more starch granules were observed in thebgal1 mutant (Figure 4B).At 1 day after switching to $\mathrm{N}$-starvedcondition, the starch granulesandlipid droplets were both accumulated in wild type (Figure 4C). However, in the bgal1 mutant, the starch granuleswere more significantly accumulated than lipid droplets (Figure 4D). Indeed, starch contents were significantly increased in the bgal1 mutant compared to wild type (Figure 4E). These observations suggest that the bgal1 mutanthas a metabolic defect in conversion of starch into the storage lipid, thus mainly accumulates starch granulerather than lipid dropletsunder $\mathrm{N}$ starvation.

\subsection{Triacylglycerol accumulation was defective in $\mathrm{N}$-starvedbgal1}

To investigate whether TAG level is conversely decreasedin thebgal 1 because of the over-accumulation of starch,weperformed time-course TAG analysis following $\mathrm{N}$ starvation. Wild type cells accumulated TAG massively by 7 days after $\mathrm{N}$ starvation; however, the bgal1 showed much lower level of TAG accumulationas indicated by the intensity of spots corresponding to TAG on thethin-layer chromatography (TLC) plate(Figure $5 A$ ). We quantified TAG levels at different time points after $\mathrm{N}$ starvation (Figure 5B). By 1 day after $\mathrm{N}$ starvation, TAG levels in thebgal1 were significantly lower by $63 \%$ of wild type. By 7 days, TAG levels in thebgal1 were about one-third of that in wild type. We next analyzed the fatty acid composition of TAG accumulated at 7 days after $\mathrm{N}$ starvation. As shown in Figure $5 \mathrm{C}$, fatty acid composition of TAG in thebgal1 was significantly different from that in wild type. The major changes involved decrease in $\mathrm{C} 18: 1 \Delta 9$ but increase in polyunsaturated fatty acids such 
as $\mathrm{C} 16: 4$ and $\mathrm{C} 18: 3 \omega 6$. Moreover, saturated fatty acid species (C16:0 and C18:0) and monounsaturated fatty acid (C18:1 111$)$ showed clear increase, and C16:1 and C16:2 exhibited considerable decrease in thebgal1. The increase in unsaturation of fatty acid in thebgal1 is likely due to the reduced flux of de novo TAG biosynthesis, because primary neosynthesis of TAG incorporates saturated and C18:1 $\Delta 9$ fatty acid species(Fan et al., 2011). To examine the metabolic capacity of de novo TAG biosynthesis in thebgal1, we analyzed timecourse TAG profiles following acetate supplementation. Because acetate is an initial precursor of fatty acid synthesis, this "acetate boost' triggers rapid induction of TAG biosynthesis, which results in cells filled with lipid droplets composed of TAG (Goodson et al., 2011). Following acetate boost, TAG levels were not increased significantly in thebgal1as compared to those in the wild type (Figures5B and 5D), suggesting that thebgal1mutant has slightly reduced capacity of de novo TAG biosynthesis.

\subsection{Metabolomicanalysis of N-replete and N-starved bgal1}

To investigate the global metabolic defect in the primary carbon metabolism in thebgal1 mutant, we performed metabolomicanalysis of some of major metabolites in the glycolysis pathway and tricarboxylic acid cycle (TCA cycle), and compared the profile between wild type and thebgal1mutant under $\mathrm{N}$-replete (Figure 6) or N-starved (Figure 7) conditions. Under N-replete growth condition, thebgal1 mutant showed significantly reduced levels of metabolites following the hydrolysis of starch, such as fructose6-phosphate (F6P), fructose1,6-bisphosphate (F16BP) and glyceraldehyde 3-phosphate (GA3P). In addition, dihydroxyacetonephosphate (DHAP), which is a substrate for 
glycerolipid biosynthesis, was not detectable. Moreover, acetyl-CoA level was significantly decreased, suggesting a reduced synthesis of fatty acid. On the other hand, metabolites related to the TCA cycle were not affected except reduced levels of citrate and isocitratein the bgal1 mutant compare with the wild type.These profiles support accumulation of starch and suggest reduced capacity of TAG biosynthesis.

Upon $\mathrm{N}$ starvation, these profiles altered dramatically. In the bgal1 mutant, some of the metabolites involved in the reaction from glucose 6phosphate (G6P) to TAG biosynthesis were increased, whereas those in the TCA cycle were decreased (Figure 7). In the glycolysis pathway, levels of F16BP, GA3P and DHAP were increased to be as high as those of WT. Remarkably, GA3P and DHAP were not detectable under N-replete condition (Figure 6) but their levels were similar between wild type and the bgal1 mutant upon $\mathrm{N}$ starvation (Figure 7). On the other hand, levels of G6P and F6P were lower in the bgal1 mutant, which are consistent with the changes in N-replete growth condition.In addition, levels of phosphoenolpyruvate (PEP) were decreased but pyruvate were increased in the bgal1 mutantupon $\mathrm{N}$ starvation. In the TCA cycle, levels of all metabolites analyzed showed significant decrease in the bgal1 mutantupon $\mathrm{N}$ starvation. This suggests decreased energy production, which may be relevant to decreased ATP level in the bgal1 mutantupon $\mathrm{N}$ starvation. Of note, acetyl-CoA level was significantly lower even under $\mathrm{N}$ starvation, suggesting consistent defect in the supply of de novo fatty acid biosynthesis both in $\mathrm{N}$-replete and $\mathrm{N}$-starved conditions. Thus, the bgal1 mutant showed characteristic metabolite profiles; while consistent decrease 
was observed for the levels of G6P, F6P and acetyl-CoA regardless of the growth condition, most of the other metabolites in glycolysis were increased but those in the TCA cycle were decreased upon $\mathrm{N}$ starvation.

\section{Discussion}

The bgal1 mutant was characterized for its enhanced accumulation of starch granules under N-replete growth condition (Figure 2). Starch is the major pool of photo-assimilated carbon source whose synthesis and degradation occur simultaneously under light condition in C. reinhardtii(Klein, 1987). The bgal1 mutant has an insertional mutation in the open reading frame of a $\beta$ galactosidase-like gene (Figure 2A). Upon N starvation, at which conversion of starch into TAG is stimulated indifferent green algae such asPseudochlorococcum sp. and C. reinhardtii(Li et al., 2011; Gardner et al., 2013), the bgal1 mutant displayed further accumulation of starch granules at the expense of TAG accumulation. While results shown here support the conclusion that BGAL1 is involved in the hydrolysis of starch and TAG accumulation during $\mathrm{N}$ starvation, we still await genetic complementation of the bgal1 mutant to confirm these effects genetically. Since C. reinhardtii is haploid and notorious for having multiple insertions and other genetic rearrangement,there is still the possibility that the effectobserved in this study might be due to second site mutations.

The growth phenotype of the bgal1 was more pronounced under photoautotrophic condition (Figure 1E) than photoheterotrophic condition (Figure 1D) under N-replete condition.In the former condition, supply of carbon 
source relies on photosynthesis. Since starch as a principal carbon sinktakespart inthe photoprotection against oxidative damage(Krishnan et al., 2015), reduced photosynthetic growth in the bgal1 may be related to starch accumulation. Indeed, the phenotypic difference between the bgal1 and wild type was much attenuated under $\mathrm{N}$-starved condition (Figure 3), at which overall photosynthetic capacity is greatly reduced (Juergens et al., 2015). The deduced amino acid sequence of BGAL1possesses a predicted $\mathrm{N}$-terminal chloroplast transit peptide (Figure S1B). Compared with wild type,microscopic observation showed that thebgal1 accumulatedmore starch granules in the chloroplasts under photoheterotrophic condition (Figure $2 \mathrm{D}$ and $2 \mathrm{E}$ ).It is possible that increased starch accumulation occurs in the chloroplasts in the bgal1 mutant, affecting chloroplast function in the maintenance of photosynthesis.

The BGAL1 encodes $\beta$-galactosidase-like enzyme, which contains glycosyl hydrolase superfamily 42 motif. In thebgal1 mutant, $\beta$-galactosidase activity in the total cell lysate was $40 \%$ of that of wild type (Figure $2 \mathrm{C}$ ), which suggests thatBGAL1 is responsible for the major activity to hydrolyzethe nonreducing terminal $\beta$-galactoside bonds. Because starch is mainly composed of $\alpha$-linked glucose, an involvement of $\beta$-galactoside in starch degradation was somewhat unexpected from the enzymatic point of view. In Arabidopsis thaliana,a homologue of $\beta$-galactosidase MUM2/BGAL6 (At5g63800) is required for swelling and extrusion of the mucilage on seed hydration by removal of galactose/galactan branches (Dean et al., 2007; Macquet et al., 2007). The AtBGAL10 (At5g63810) was suggested to act on nonreducing ends 
of xyloglucan for appropriate silique elongation (Sampedro et al., 2012). Recently, a novel agarolytic $\beta$-galactosidase was reported in Vibrio sp. EJY3 that can act at the nonreducing end of agarooligosaccharides to release galactose (Lee et al., 2014). These evidences suggest that various $\beta$ galactosidasehomologuesshow different substrate specificity. It is possible that $\beta$-galactosidaseis required at some step in hydrolyzing starch in C. reinhardtii. In future effort, it may be helpful to conduct in vitro assay using recombinant BGAL1 protein and starch purified from the bgal1 mutant. Analyzing the resulting polysaccharide chain patterns by glycomics technology will elucidate the role of BGAL1, and further the whole metabolic steps, in starch hydrolysis.

The bgal1 mutant showed reducedTAG accumulation under $\mathrm{N}$ starvation (Figure 5).The fatty acid composition of TAG in the bgal1 showed significant changes from that in wild type (Figure 5C) but is similar to the profile of pgd1 mutant ( $\mathrm{Li}$ et al, 2012). Because PGD1 is the chloroplast-localizedlipase involved in the de novo synthesis of TAG, the similar changes in the fatty acid compositionbetween bgal1 and pgd1suggests that the bgal1 is defective in de novo TAG biosynthesis as well. TAG is assembled by acyl groups and a glycerol backbone. While acyl groups are provided by the fatty acid synthesis originating from acetyl-CoA, the glycerol backbone is derived from DHAP. In the metabolomic profiling, levels of both acetyl-CoA and DHAP were decreased in the bgal1 mutant under $\mathrm{N}$-replete growth condition (Figure 6). Upon $\mathrm{N}$ starvation, DHAP level was recovered in the bgal1 mutant whereas acetyl-CoA level remained lower (Figure 7). However, acetate boost experiment, which stimulates FA synthesis, did not rescue the TAG levels (Figure 5D). This 
suggests that reduced TAG levels in N-starved bgal1 mutant is not mainly due to the reduced metabolic flux of fatty acid biosynthesis but presumably for the reduced supply of glycerol backbone.

Our metabolomics profiling of the bgal1 mutant provided further insight into the metabolic alteration underlying the bgal1 mutant. The sta6 mutant is a widely used mutant of $C$. reinhardtii which increases TAG level because an enzyme for starch biosynthesis is mutated (Zabawinski et al., 2001; Work et al., 2010). A recent metabolomic study of the sta 6 showed increased levels of metabolites related to glycolysis and TCA cycle(Blaby et al., 2013; Krishnan et al., 2015). Our metabolite analysis showed that the bgal1 mutant reduced levels of metabolites inglycolysis and TCA cycle,especially under N starvation (Figure 7).This contrasting difference in metabolite profiles between bgal1 and sta6may support the proposal that BGAL1 is involved in the hydrolysis of starch.

\section{Conclusion}

We isolated and characterized a new class of $\beta$-galactosidase BGAL1 in C. reinhardtii through isolation of its mutant, which may be involved in the hydrolysis of starch and affect TAG accumulation upon $\mathrm{N}$ starvation. This study provides a new mutant model contrasting to sta6 in investigating $\mathrm{N}$ starvationinduced TAG accumulation, as well as metabolic insight into TAG biosynthesis in C. reinhardtii.

\section{Author contributions}

C.-H.H. performed overall experiments. K. K. designed research and performed molecular construction. Y. N. conceived and designed research, and wrote the 
manuscript.All authors commented on the manuscript and approved the contents.

\section{Acknowledgements}

We thank staffs in Institute of Plant and Microbial Biology, Academia Sinicafor their technical assistance; Hsiu-An Chu for providing equipments to assay photosynthetic activity, Ming-Yang Ho in overall algal experiments, Wann-Neng Jane for microscopic observation and Yu-Ching Wu for metabolomics analyses. Y.N. was supported by PRESTO, Japan Science and Technology Agency and core budget from the Institute of Plant and Microbial Biology, Academia Sinica, Taipei.

\section{REFERENCES}

Arnon, D.I., Allen, M.B., and Whatley, F.R. (1954) Photosynthesis by isolated chloroplasts. Nature.174, 394-396.

Blaby, I.K., Glaesener, A.G., Mettler, T., Fitz-Gibbon, S.T., Gallaher, S.D., Liu, B., Boyle, N.R., Kropat, J., Stitt, M., Johnson, S., Benning, C., Pellegrini, M., Casero, D., and Merchant, S.S. (2013) Systems-level analysis of nitrogen starvation-induced modifications of carbon metabolism in a Chlamydomonas reinhardtii starchless mutant. Plant Cell.25, 4305-4323.

Boyle, N.R., Page, M.D., Liu, B., Blaby, I.K., Casero, D., Kropat, J., Cokus, S.J., Hong-Hermesdorf, A., Shaw, J., Karpowicz, S.J., Gallaher, S.D., Johnson, S., Benning, C., Pellegrini, M., Grossman, A., and 
Merchant, S.S. (2012) Three acyltransferases and nitrogen-responsive regulator are implicated in nitrogen starvation-induced triacylglycerol accumulation in Chlamydomonas. J Biol Chem.287, 15811-15825.

Breuer, G., Lamers, P.P., Martens, D.E., Draaisma, R.B., and Wijffels, R.H. (2012) The impact of nitrogen starvation on the dynamics of triacylglycerol accumulation in nine microalgae strains. Bioresour Technol.124, 217-226.

Cakmak, T., Angun, P., Ozkan, A.D., Cakmak, Z., Olmez, T.T., and Tekinay, T. (2012) Nitrogen and sulfur deprivation differentiate lipid accumulation targets of Chlamydomonas reinhardtii. Bioengineered.3, 343-346.

Dean, G.H., Zheng, H., Tewari, J., Huang, J., Young, D.S., Hwang, Y.T., Western, T.L., Carpita, N.C., McCann, M.C., Mansfield, S.D., and Haughn, G.W. (2007) The Arabidopsis MUM2 gene encodes a betagalactosidase required for the production of seed coat mucilage with correct hydration properties. Plant Cell.19, 4007-4021.

Dent, R.M., Haglund, C.M., Chin, B.L., Kobayashi, M.C., and Niyogi, K.K. (2005) Functional genomics of eukaryotic photosynthesis using insertional mutagenesis of Chlamydomonas reinhardtii. Plant Physiol.137, 545-556.

Doebbe, A., Keck, M., La Russa, M., Mussgnug, J.H., Hankamer, B., Tekce, E., Niehaus, K., and Kruse, O..(2010) The interplay of proton, electron, and metabolite supply for photosynthetic $\mathrm{H} 2$ production in Chlamydomonas reinhardtii. J Biol Chem285, 30247-30260. 
Emanuelsson, O., Nielsen, H., Brunak, S., and von Heijne, G. (2000) Predicting subcellular localization of proteins based on their $\mathrm{N}$-terminal amino acid sequence. J Mol Biol.300, 1005-1016.

Fan, J., Andre, C., and Xu, C. (2011) A chloroplast pathway for the de novo biosynthesis of triacylglycerol in Chlamydomonas reinhardtii. FEBS Lett.585, 1985-1991.

Folch, J., Lees, M., and Sloane Stanley, G.H. (1957) A simple method for the isolation and purification of total lipides from animal tissues. $J$ Biol Chem.226, 497-509.

Gardner, R.D., Lohman, E., Gerlach, R., Cooksey, K.E., and Peyton, B.M. (2013) Comparison of $\mathrm{CO}(2)$ and bicarbonate as inorganic carbon sources for triacylglycerol and starch accumulation in Chlamydomonas reinhardtii. Biotechnol Bioeng.110, 87-96.

Goodson, C., Roth, R., Wang, Z.T., and Goodenough, U. (2011) Structural correlates of cytoplasmic and chloroplast lipid body synthesis in Chlamydomonas reinhardtii and stimulation of lipid body production with acetate boost. Eukaryot Cell.10, 1592-1606.

Gorman, D.S., and Levine, R.P. (1965) Cytochrome $f$ and plastocyanin: their sequence in the photosynthetic electron transport chain of Chlamydomonas reinhardii. Proc Natl Acad Sci U S A.54, 1665-1669.

Hung, C.H., Huang, J.Y., Chiu, Y.F., and Chu, H.A.(2007) Site-directed mutagenesis on the heme axial-ligands of cytochrome b559 in photosystem II by using cyanobacteria Synechocystis PCC 6803. Biochim Biophys Acta1767, 686-693. 
Hung, C.H., Ho, M.Y., Kanehara, K., and Nakamura, Y. (2013) Functional study of diacylglycerol acyltransferase type 2 family in Chlamydomonas reinhardtii. FEBS Lett.587, 2364-2370.

Hung, C.H., Endo, K., Kobayashi, K., Nakamura, Y., and Wada, H. (2015) Characterization of Chlamydomonas reinhardtiiphosphatidylglycerophosphate synthase in Synechocystis sp. PCC 6803. Front. Microbiol.6, 842.

Juergens, M.T., Deshpande, R.R., Lucker, B.F., Park, J.J., Wang, H., Gargouri, M., Holguin, F.O., Disbrow, B., Schaub, T., Skepper, J.N., Kramer, D.M., Gang, D.R., Hicks, L.M., and Shachar-Hill, Y. (2015) The regulation of photosynthetic structure and function during nitrogen deprivation in Chlamydomonas reinhardtii. Plant Physiol.167, 558-573.

Kindle, K.L. (1990) High-frequency nuclear transformation of Chlamydomonas reinhardtii. Proc Natl Acad Sci U S A.87, 1228-1232.

Klein, U. (1987) Intracellular Carbon Partitioning in Chlamydomonas reinhardtii. Plant Physiol.85, 892-897.

Krishnan, A., Kumaraswamy, G.K., Vinyard, D.J., Gu, H., Ananyev, G., Posewitz, M.C., and Dismukes, G.C. (2015) Metabolic and photosynthetic consequences of blocking starch biosynthesis in the green alga Chlamydomonas reinhardtii sta6 mutant. Plant J.81, 947-960.

Kropat, J., Hong-Hermesdorf, A., Casero, D., Ent, P., Castruita, M., Pellegrini, M., Merchant, S.S., and Malasarn, D. (2011) A revised mineral nutrient supplement increases biomass and growth rate in Chlamydomonas reinhardtii. Plant J.66, 770-780. 
Lee, C.H., Kim, H.T., Yun, E.J., Lee, A.R., Kim, S.R., Kim, J.H., Choi, I.G., and Kim, K.H. (2014) A novel agarolytic beta-galactosidase acts on agarooligosaccharides for complete hydrolysis of agarose into monomers. Appl Environ Microbiol.80, 5965-5973.

Li, X., Moellering, E.R., Liu, B., Johnny, C., Fedewa, M., Sears, B.B., Kuo, M.H., and Benning, C. (2012) A galactoglycerolipid lipase is required for triacylglycerol accumulation and survival following nitrogen deprivation in Chlamydomonas reinhardtii. Plant Cell.24, 4670-4686.

Li, Y., Han, D., Sommerfeld, M., and Hu, Q. (2011) Photosynthetic carbon partitioning and lipid production in the oleaginous microalga Pseudochlorococcum sp. (Chlorophyceae) under nitrogen-limited conditions. Bioresour Technol.102, 123-129.

Li, Y., Han, D., Hu, G., Sommerfeld, M., and Hu, Q. (2010a) Inhibition of starch synthesis results in overproduction of lipids in Chlamydomonas reinhardtii. Biotechnol Bioeng.107, 258-268.

Li, Y., Han, D., Hu, G., Dauvillee, D., Sommerfeld, M., Ball, S., and Hu, Q. (2010b) Chlamydomonas starchless mutant defective in ADP-glucose pyrophosphorylase hyper-accumulates triacylglycerol. Metab Eng.12, 387-391.

Macquet, A., Ralet, M.C., Loudet, O., Kronenberger, J., Mouille, G., MarionPoll, A., and North, H.M. (2007) A naturally occurring mutation in an Arabidopsis accession affects a beta-D-galactosidase that increases the hydrophilic potential of rhamnogalacturonan I in seed mucilage. Plant Cell.19, 3990-4006. 
Matthew, T., Zhou, W., Rupprecht, J., Lim, L., Thomas-Hall, S.R., Doebbe, A., Kruse, O., Hankamer, B., Marx, U.C., Smith, S.M., and Schenk, P.M. (2009) The metabolome of Chlamydomonas reinhardtii following induction of anaerobic $\mathrm{H} 2$ production by sulfur depletion. $\mathrm{J}$ Biol Chem.284, 23415-23425.

Molnar, A., Bassett, A., Thuenemann, E., Schwach, F., Karkare, S., Ossowski, S., Weigel, D., and Baulcombe, D. (2009) Highly specific gene silencing by artificial microRNAs in the unicellular alga Chlamydomonas reinhardtii. Plant J.58, 165-174.

Mouille, G., Maddelein, M.L., Libessart, N., Talaga, P., Decq, A., Delrue, B., and Ball, S. (1996) Preamylopectin Processing: A Mandatory Step for Starch Biosynthesis in Plants. Plant Cell.8, 1353-1366.

Msanne, J., Xu, D., Konda, A.R., Casas-Mollano, J.A., Awada, T., Cahoon, E.B., and Cerutti, H. (2012) Metabolic and gene expression changes triggered by nitrogen deprivation in the photoautotrophically grown microalgae Chlamydomonas reinhardtii and Coccomyxa sp. C-169. Phytochemistry.75, 50-59.

Nakamura, Y., Arimitsu, H., Yamaryo, Y., Awai, K., Masuda, T., Shimada, H., Takamiya, K., and Ohta, H. (2003) Digalactosyldiacylglycerol is a major glycolipid in floral organs of Petunia hybrida. Lipids.38, 1107-1112.

Newman, S.M., Boynton, J.E., Gillham, N.W., Randolph-Anderson, B.L., Johnson, A.M., and Harris, E.H. (1990) Transformation of chloroplast ribosomal RNA genes in Chlamydomonas: molecular and genetic characterization of integration events. Genetics.126, 875-888. 
Nielsen, D.A., Chou, J., MacKrell, A.J., Casadaban, M.J., and Steiner, D.F. (1983) Expression of a preproinsulin-beta-galactosidase gene fusion in mammalian cells. Proc Natl Acad Sci U S A.80, 5198-5202.

Ramazanov, A., and Ramazanov, Z. (2006) Isolation and characterization of a starchless mutant of Chlorella pyrenoidosa STL-PI with a high growth rate, and high protein and polyunsaturated fatty acid content. Phycological Research.54, 255-259.

Sampedro, J., Gianzo, C., Iglesias, N., Guitian, E., Revilla, G., and Zarra, I. (2012) AtBGAL10 is the main xyloglucan beta-galactosidase in Arabidopsis, and its absence results in unusual xyloglucan subunits and growth defects. Plant Physiol.158, 1146-1157.

Sanjaya, Durrett, T.P., Weise, S.E., and Benning, C. (2011) Increasing the energy density of vegetative tissues by diverting carbon from starch to oil biosynthesis in transgenic Arabidopsis. Plant Biotechnol J.9, 874-883.

Sanjaya, Miller, R., Durrett, T.P., Kosma, D.K., Lydic, T.A., Muthan, B., Koo, A.J., Bukhman, Y.V., Reid, G.E., Howe, G.A., Ohlrogge, J., and Benning, C. (2013) Altered lipid composition and enhanced nutritional value of Arabidopsis leaves following introduction of an algal diacylglycerol acyltransferase 2. Plant Cell.25, 677-693.

Sueoka, N. (1960) Mitotic replication of deoxyribonucleic acid in Chlamydomonas reinhardi. Proc Natl Acad Sci U S A.46, 83-91.

Wang, H.T., Meng, Y.Y., Cao, X.P., Ai, J.N., Zhou, J.N., Xue, S., and Wang, W.L. (2015) Coordinated response of photosynthesis, carbon assimilation, and triacylglycerol accumulation to nitrogen starvation in 
the marine microalgae Isochrysis zhangjiangensis (Haptophyta). Bioresour Technol.177, 282-288.

Wang, Z.T., Ullrich, N., Joo, S., Waffenschmidt, S., and Goodenough, U. (2009) Algal lipid bodies: stress induction, purification, and biochemical characterization in wild-type and starchless Chlamydomonas reinhardtii. Eukaryot Cell.8, 1856-1868.

Work, V.H., Radakovits, R., Jinkerson, R.E., Meuser, J.E., Elliott, L.G., Vinyard, D.J., Laurens, L.M., Dismukes, G.C., and Posewitz, M.C. (2010) Increased lipid accumulation in the Chlamydomonas reinhardtii sta7-10 starchless isoamylase mutant and increased carbohydrate synthesis in complemented strains. Eukaryot Cell.9, 1251-1261.

Yoon, K., Han, D., Li, Y., Sommerfeld, M., and Hu, Q. (2012) Phospholipid:diacylglycerol acyltransferase is a multifunctional enzyme involved in membrane lipid turnover and degradation while synthesizing triacylglycerol in the unicellular green microalga Chlamydomonas reinhardtii. Plant Cell.24, 3708-3724.

Zabawinski, C., Van Den Koornhuyse, N., D'Hulst, C., Schlichting, R., Giersch, C., Delrue, B., Lacroix, J.M., Preiss, J., and Ball, S. (2001) Starchless mutants of Chlamydomonas reinhardtii lack the small subunit of a heterotetrameric ADP-glucose pyrophosphorylase. J Bacteriol.183, 1069-1077. 


\section{Figure Legend}

Figure 1.Phenotype of the bgal1 mutant under photoheterotrophic and photoautotrophic growth conditions. (A) Plate culture of wild type and thebgal1 mutant in photoheterotrophic growth condition in TAP media. (B) Relative transcript level of MGD1 in wild type and the bgal1 mutant. Gene expression was normalized to $A C T 1$. Data were averaged by 3 technical replicates in the same run and 3 biological replicates in separate runs. (C) Time-course measurement of chlorophyll contents in wild type and thebgal1 mutant under photoheterotrophic growth condition in TAP media. (D-E) Growth of wild type and thebgal1 mutant in photoheterotrophic condition in TAP media (D) or photoautotrophic condition in HS media $(E)$. ( $F)$ Measurement of net electron transfer of the bgal1 mutant in TAP media.Data are averaged by 3 biological replicates with SD.Asterisks indicate significance by Student's $t$-test $(P$ value: ${ }^{* *}<0.01$ ).WT, wild type; MGD1, monogalactosyldiacylglycerolsynthase 1.

Figure 2.Isolation and transmission electron microscopy observation of cells of wild type and the bgal1 mutant. (A) Position of transgene insertion in the bgal1 mutant. Positions of primers used for PCR-based genotyping are indicated by arrows. (B) Relative transcript level of BGAL1 in wild type and the bgal1 mutant. Gene expression levels were normalized to that of $A C T 1$. Data were averaged by 3 technical replicates in the same run and 3 biological replicates in separate runs. (C) Total $\beta$-galactosidase activity in the cell lysate of wild type and the bgal1 mutant. Data are mean \pm SD from 3 biological replicates. An **asterisk indicates significance by Student's $t$ test $(P<0.01)$. (D, E) Whole cell images of wild type (D) and the bgal1 mutant (E). Bars $=1 \mu \mathrm{m}$. $(F, G)$ Magnified view of $(F)$ and $(G)$ indicating stacking of the thylakoid membranes. Bars $=0.4 \mu \mathrm{m}$. Cells were photoheterotrophically cultured in TAP media to a density of $3 \sim 5 \times 10^{6}$ cells $\mathrm{mL}^{-1}$ for observation. WT, wild type; BGAL1, $\beta$-galactosidase 1 .

Figure 3.Phenotype of the bgal1 mutant under $\mathrm{N}$ starvation. (A) Time-course observation of pigment color in the culture of thebgal1 mutant upon $\mathrm{N}$ starvation. (B) Growth of the bgal1 mutant upon N starvation measured by cell number. (C) Decrease in chlorophyll contents of wild type and the bgal1 mutant cells under $\mathrm{N}$ starvation. Data are averaged by 3 biological replicates with SD. WT, wild type.

Figure 4.Transmission electron microscopy observation of $\mathrm{N}$-starved cells of wild type ( $A$ and $C$ ) and the bgal1 mutant (B and $D$ ) and quantification of starch contents (E). Cells were cultured in N-replete condition to a density of $\sim 3 \times 10^{6}$ cells $\mathrm{mL}^{-1}$ before transferring to $\mathrm{N}$-starved cultures to a final cell density of $2 \times 10^{6}$ cells $\mathrm{mL}^{-1}$. Samples were taken at the time of transferring to $\mathrm{N}$-starved condition (A, B), 1 day (C, D) and 5 days after the transfer for microscopy observation. Bars $=1 \mu \mathrm{m}$. 
Figure 5.TAG analysis in N-starved bgal1 mutant. (A) A thin layer chromatography image of time-course TAG accumulation in the bgal1 mutant. Amount of lipid loaded on each lane was normalized by the cell number. (B) Time-course profile of TAG levels in the wild type and bgal1 mutant following $\mathrm{N}$ starvation.(C) Fatty acid composition of TAG in the wild type and bgal1 mutant at 7 days following $\mathrm{N}$ starvation. (D) Time-course profile of TAG levels following $\mathrm{N}$ starvation with acetate boost. Data are averaged by 3 biological replicates with SD. Asterisks indicate significance by Student's $t$-test $\left(P\right.$ value; ${ }^{*}<0.05,{ }^{* *}<$ 0.01). WT, wild type; TAG, triacylglycerol; FA, fatty acid.

Figure 6.Metabolomic profiling of compounds in glycolysis pathway and TCA cyclein wild type and thebgal/underN-replete condition. Cells were cultured in $\mathrm{N}$-repletecondition to a density of $\sim 3 \times 10^{6}$ cells $\mathrm{mL}^{-1}$. Metabolite levelswere shown by fold changein thebgal1relative to that of wild type in N-replete condition.Data are mean \pm SD from 3 biological replicates. Asterisks indicate significance by Student's $t$-test $\left(P\right.$ value: $\left.{ }^{*}<0.01 ;{ }^{* *}<0.0001\right)$. G6P,glucose 6phosphate;G1P, glucose 1-phosphate; F6P, fructose 6-phosphate;F16BP, fructose 1,6-bisphosphate;GA3P,glyceraldehyde3-phosphate;3-PGA, 3phosphoglycerate; DHAP, dihydroxyacetone phosphate;PEP,phosphoenolpyruvate; G3P, glycerol 3-phosphate; LysoPA, lysophosphatidic acid; PA, phosphatidic acid; DAG, sn-1,2-diacylglycerol; TAG, triacylglycerol.

Figure 7.Metabolomic profiling of compounds in glycolysis pathway and TCA cyclein wild type and thebgal1underN-starved condition. Cells were cultured in $\mathrm{N}$-replete condition to a density of $\sim 3 \times 10^{6}$ cells $\mathrm{mL}^{-1}$ before transferring to $\mathrm{N}$ starved condition to a final cell density of $2 \times 10^{6}$ cells $\mathrm{mL}^{-1}$. Samples were taken at 5 days after the transfer for metabolite analysis.Metabolite profileswere shown by fold changein thebgal/relative to that of wild type in N-starved condition.Data are mean \pm SD from 3 biological replicates. Asterisks indicate significance by Student's $t$-test $\left(P\right.$ value: $\left.{ }^{*}<0.01 ;{ }^{* *}<0.0001\right)$. See Figure 6 for abbreviations. 

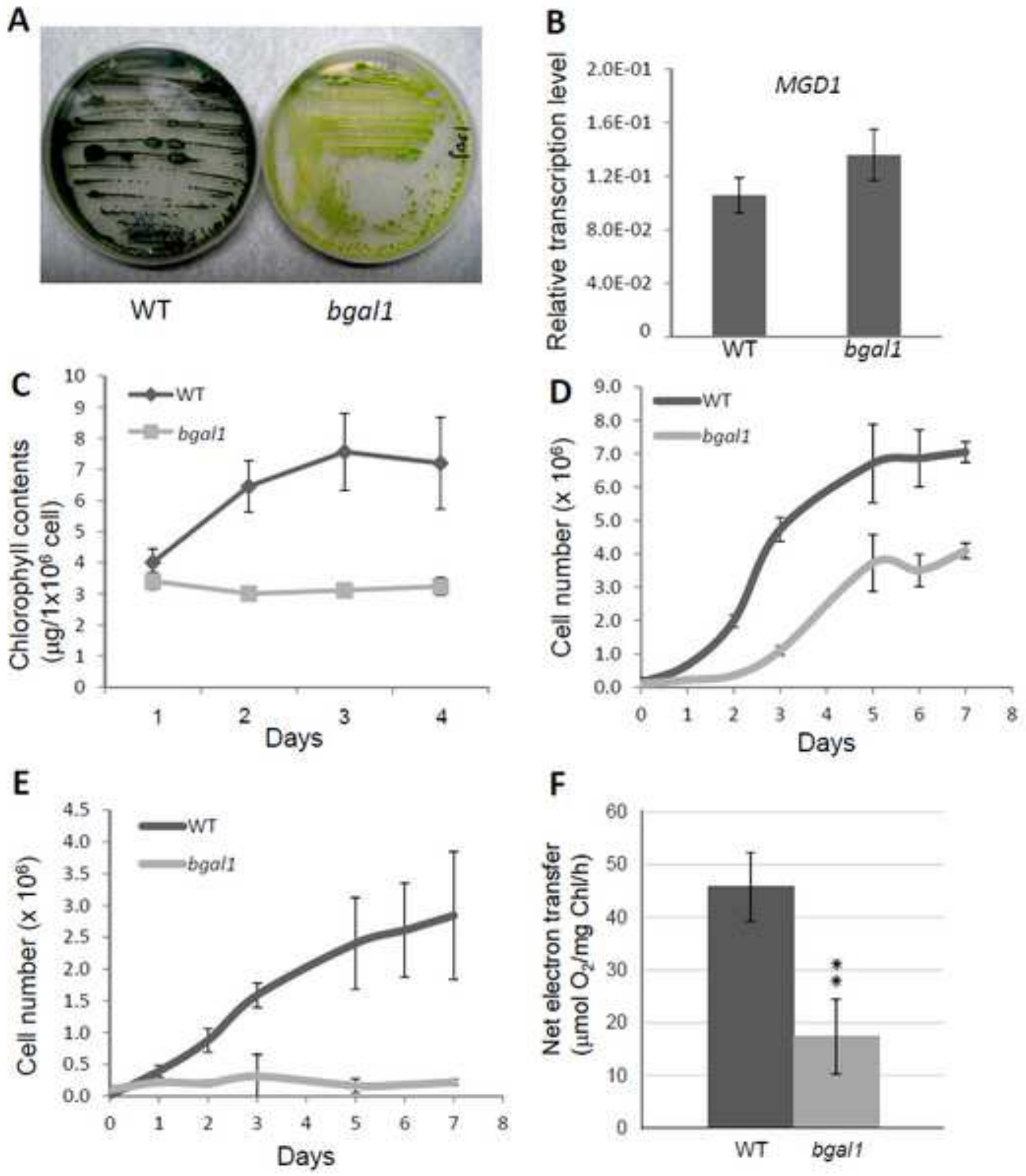
A

B

Cre02.g119700 CATCCCCAAGCA...
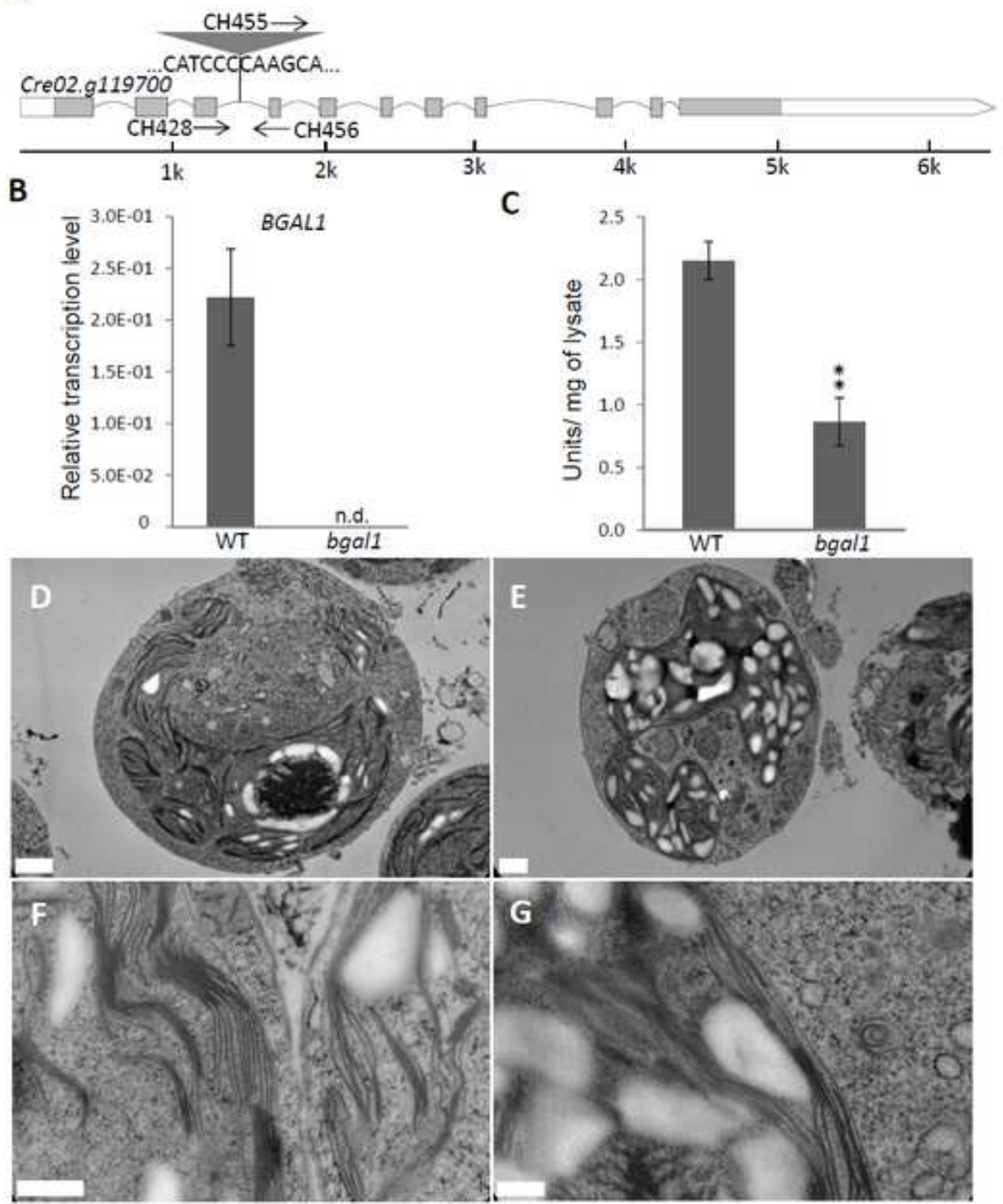

Figure 2

G

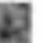

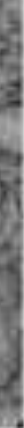


A

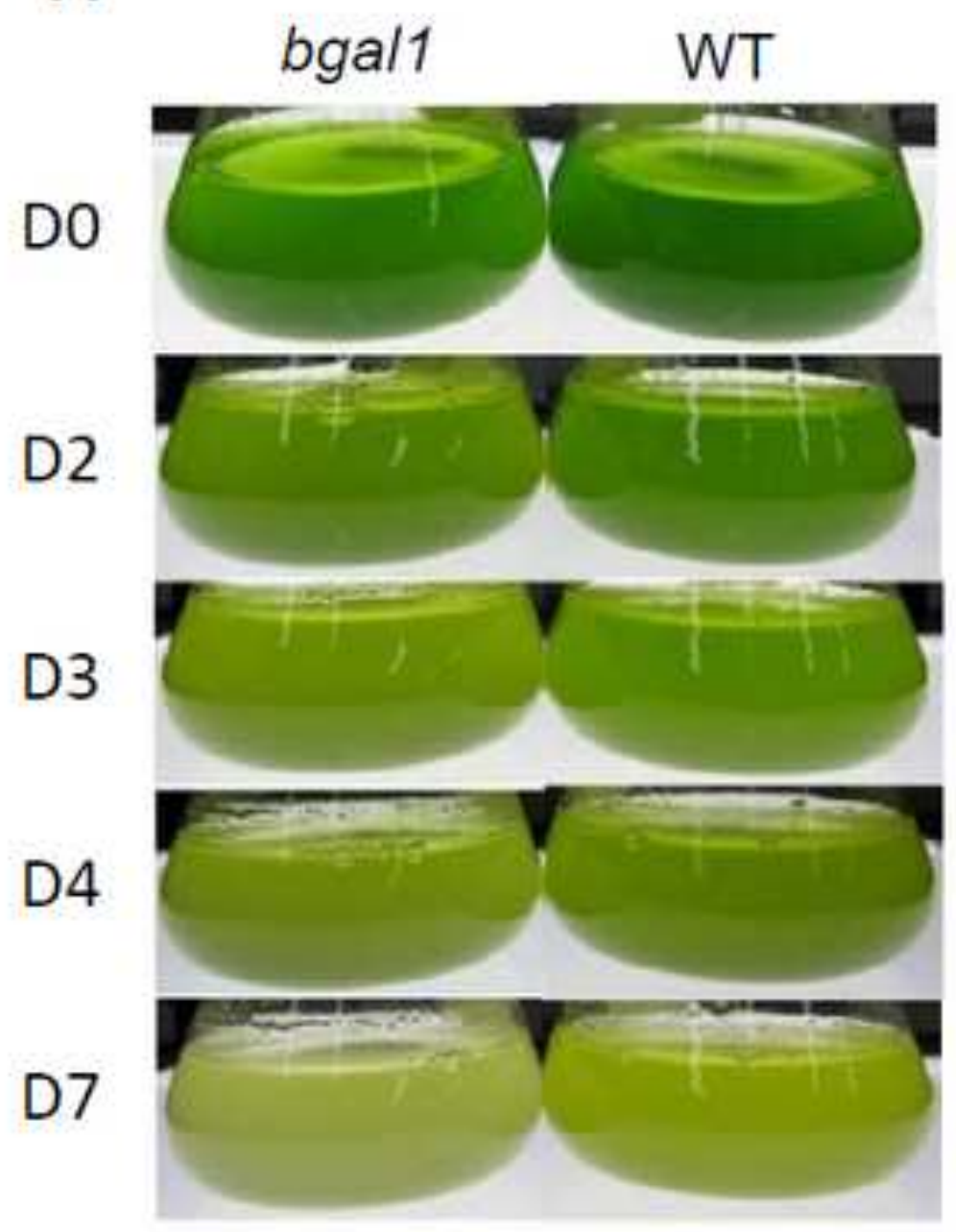

B

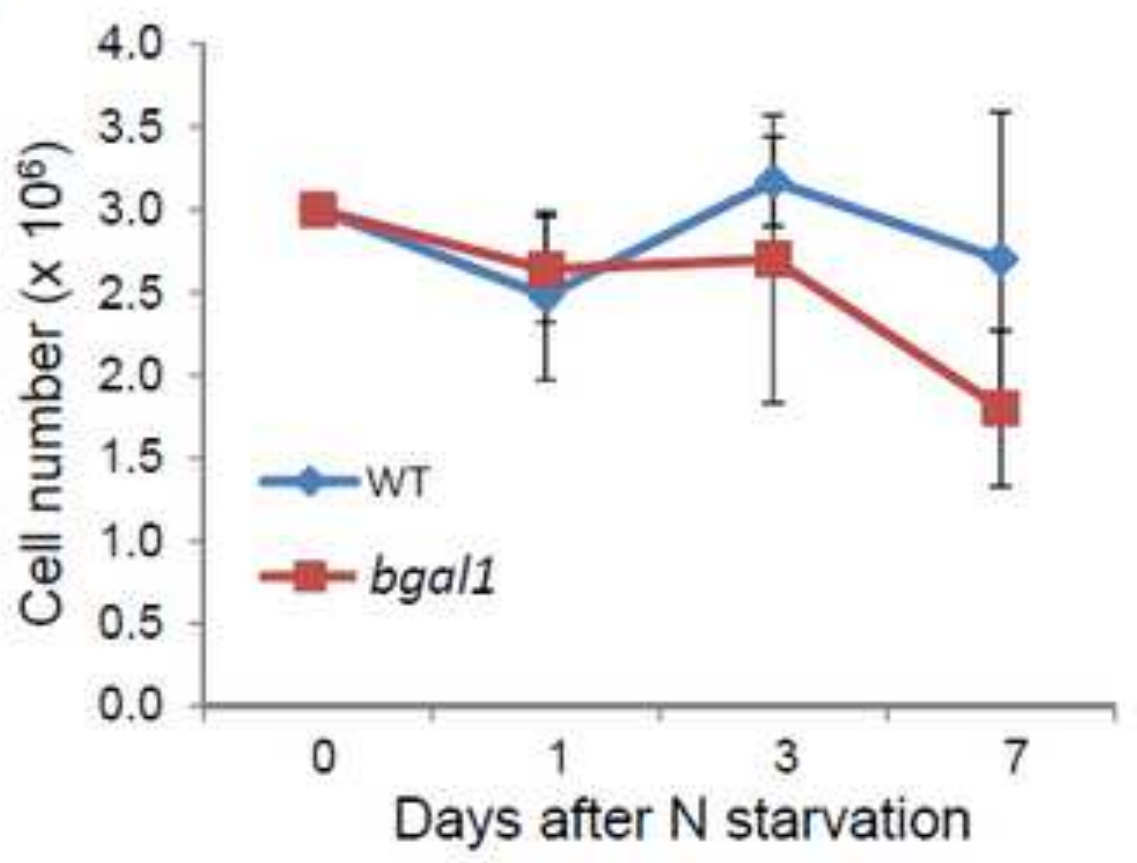

C

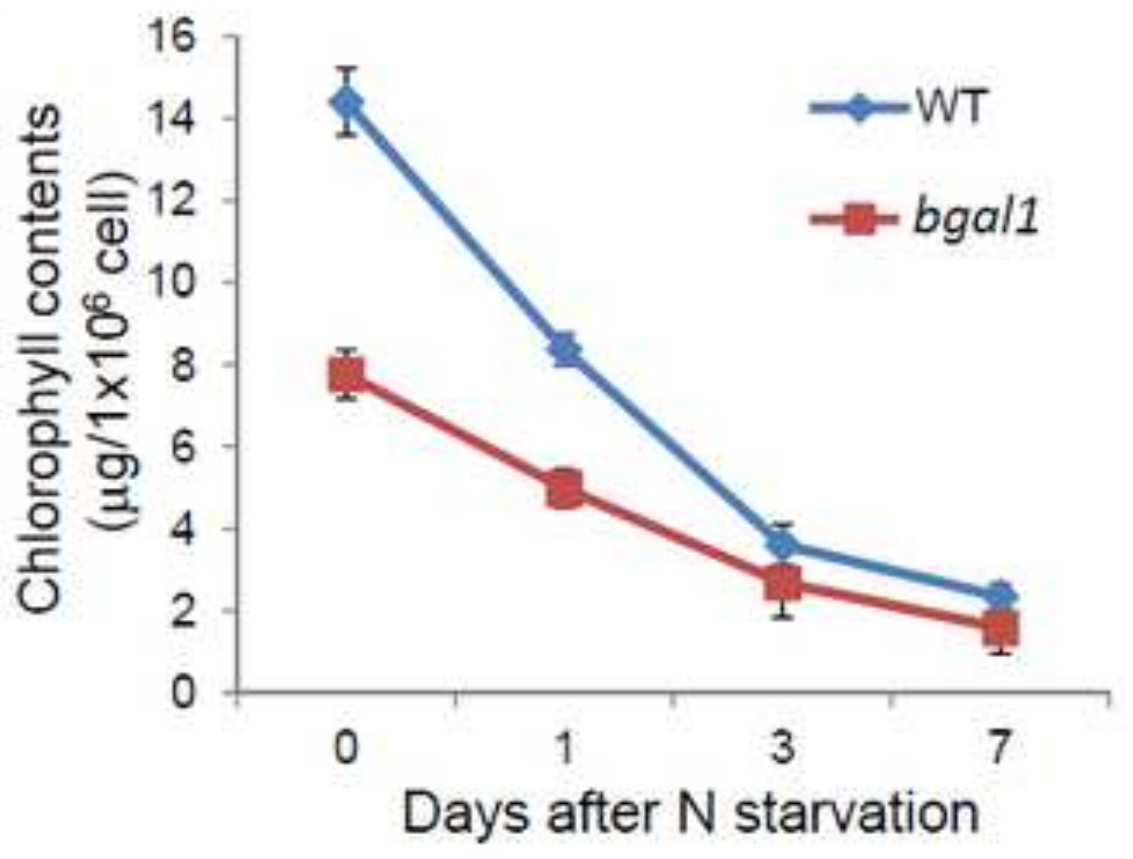



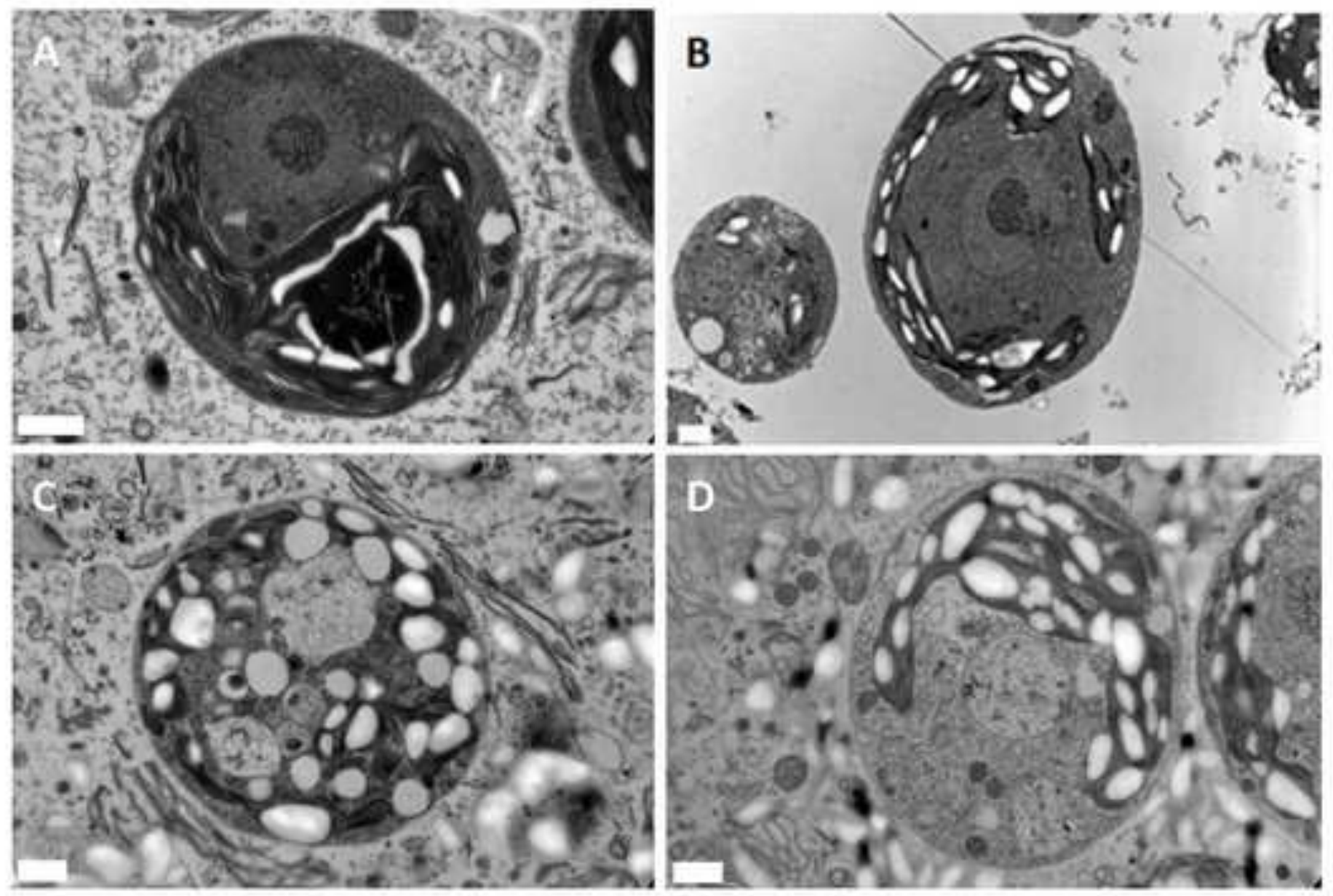

E

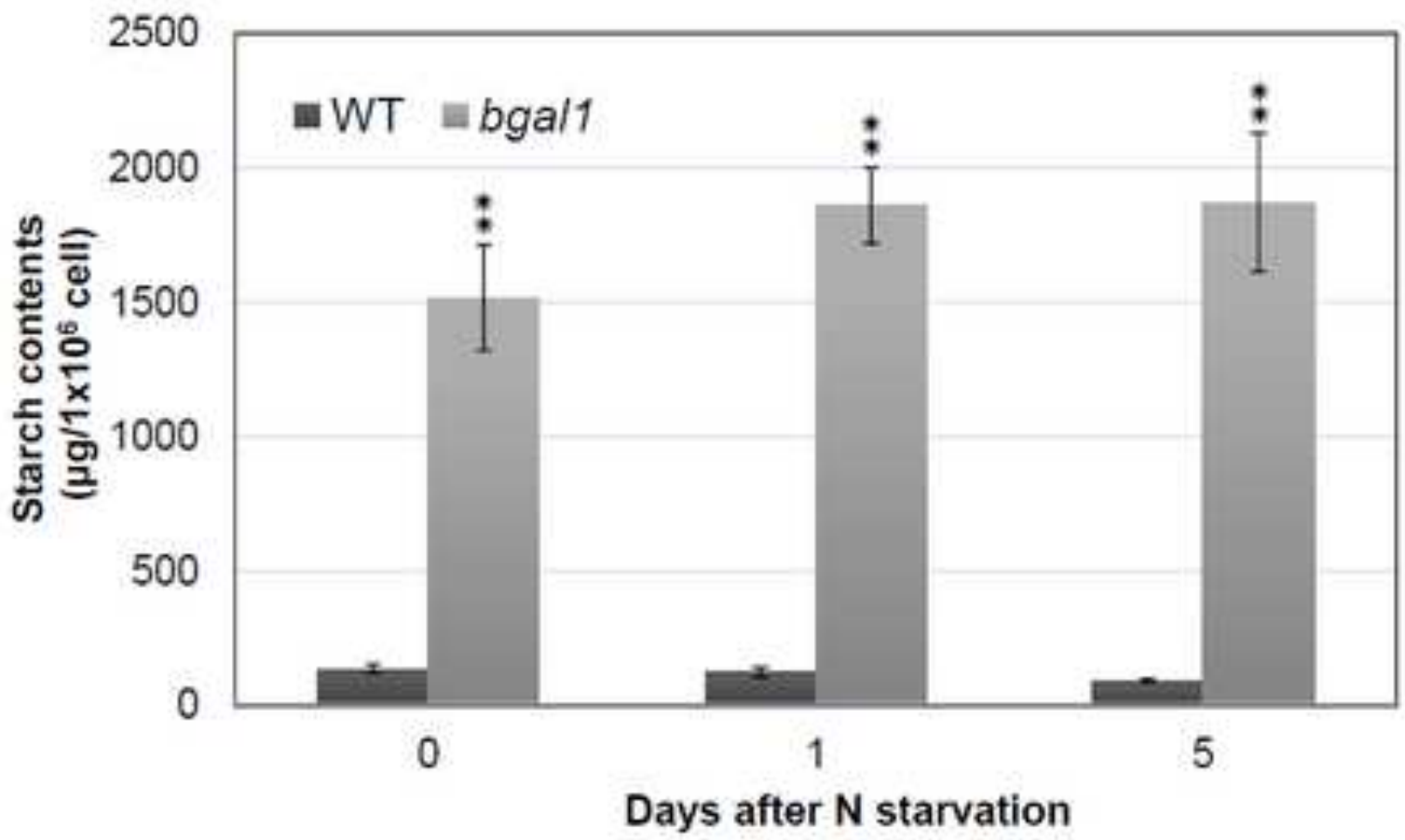


A

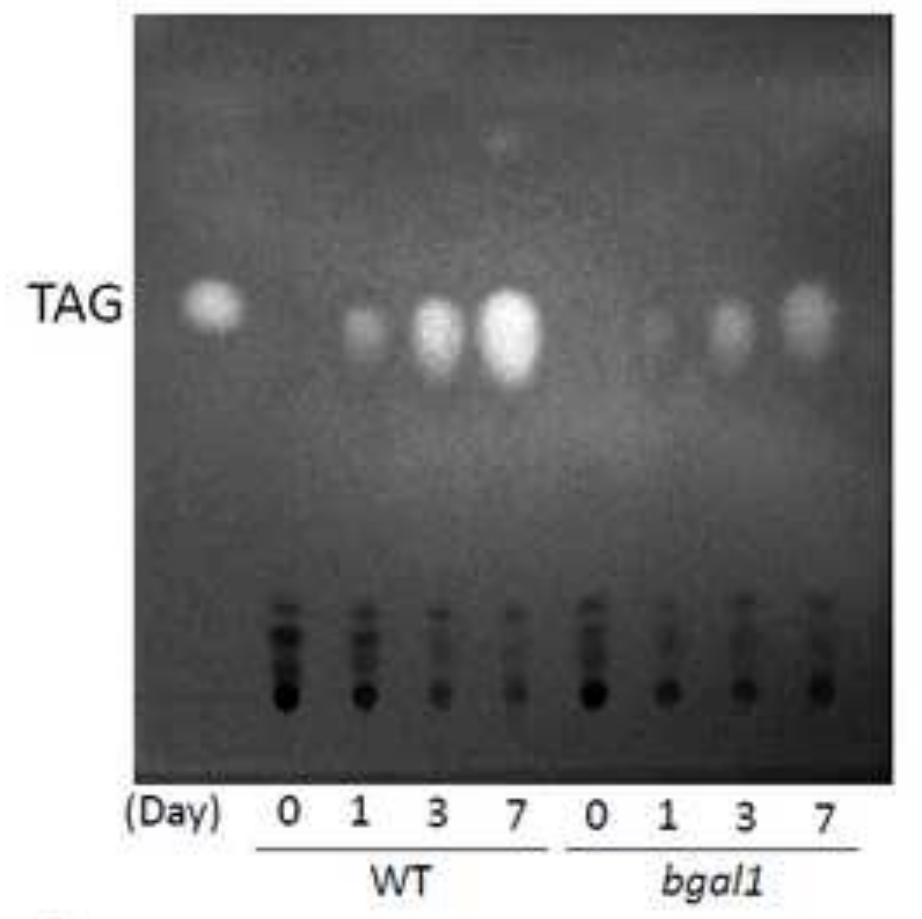

C

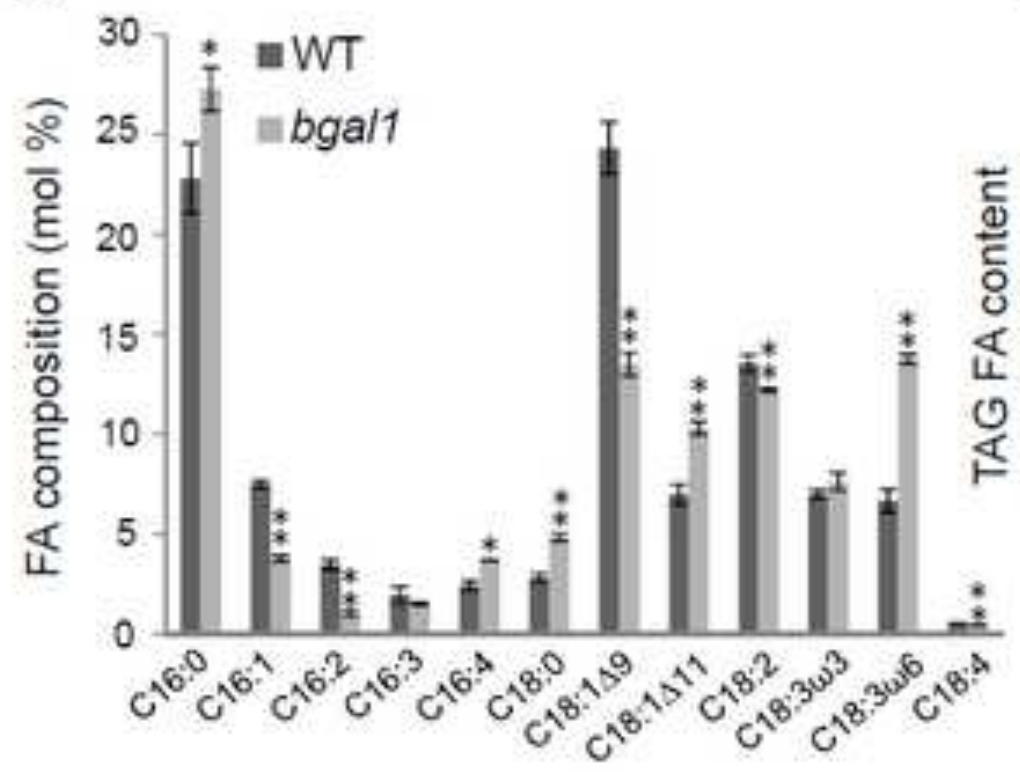

B

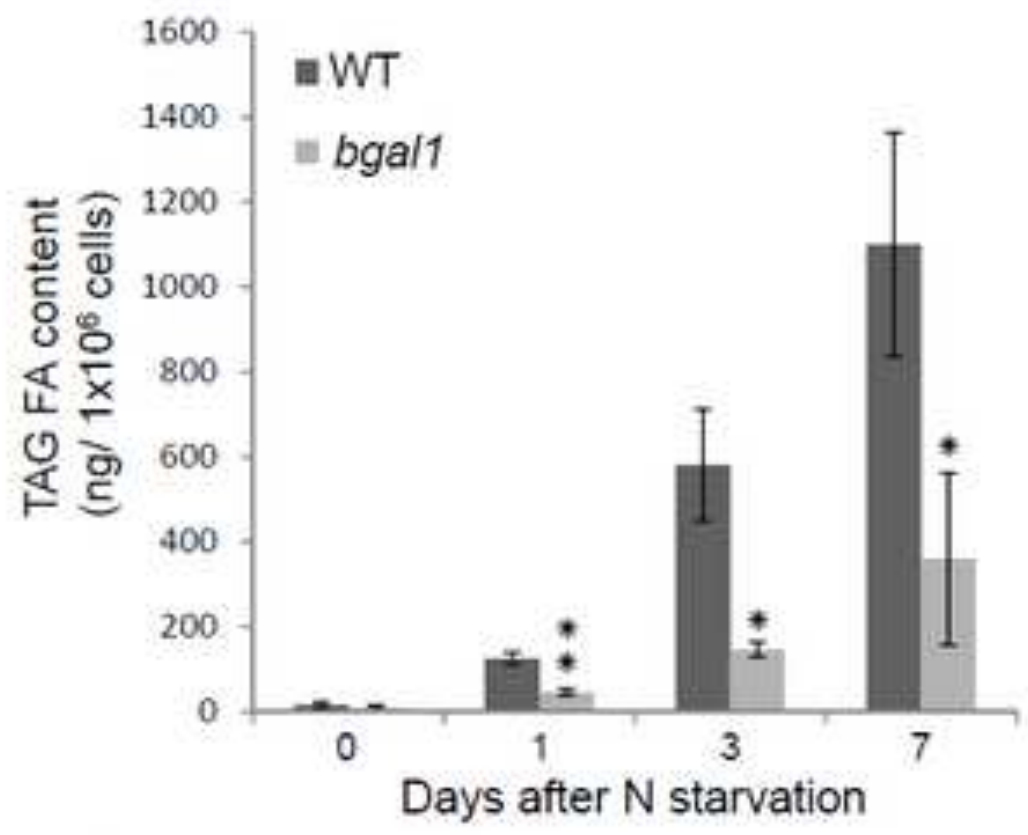

D

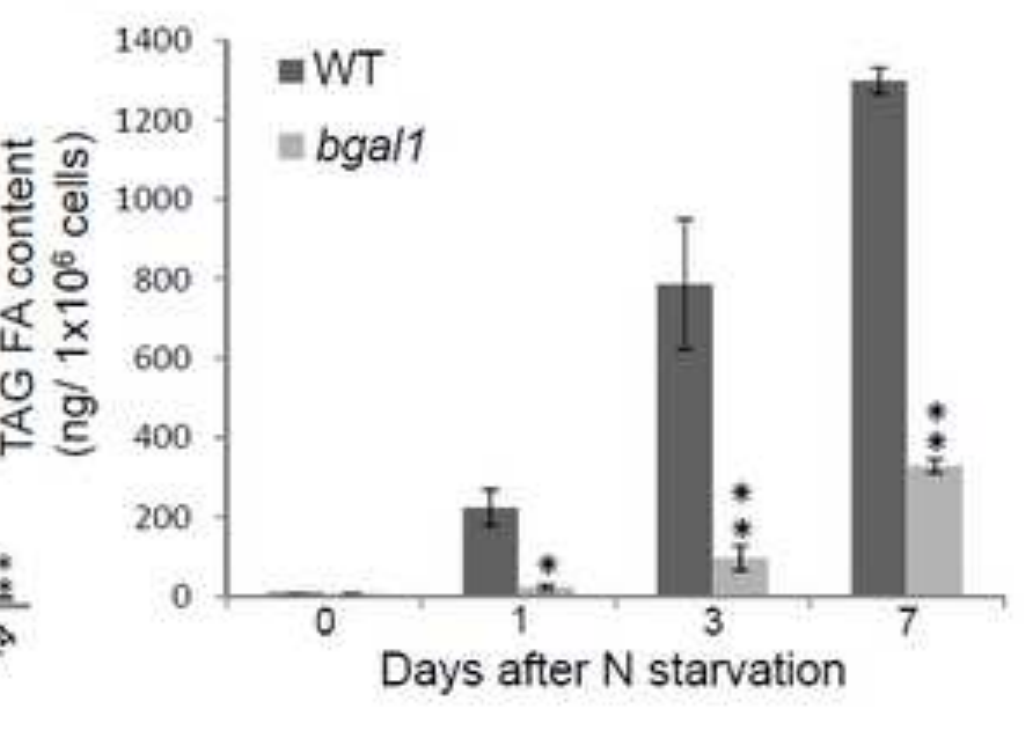




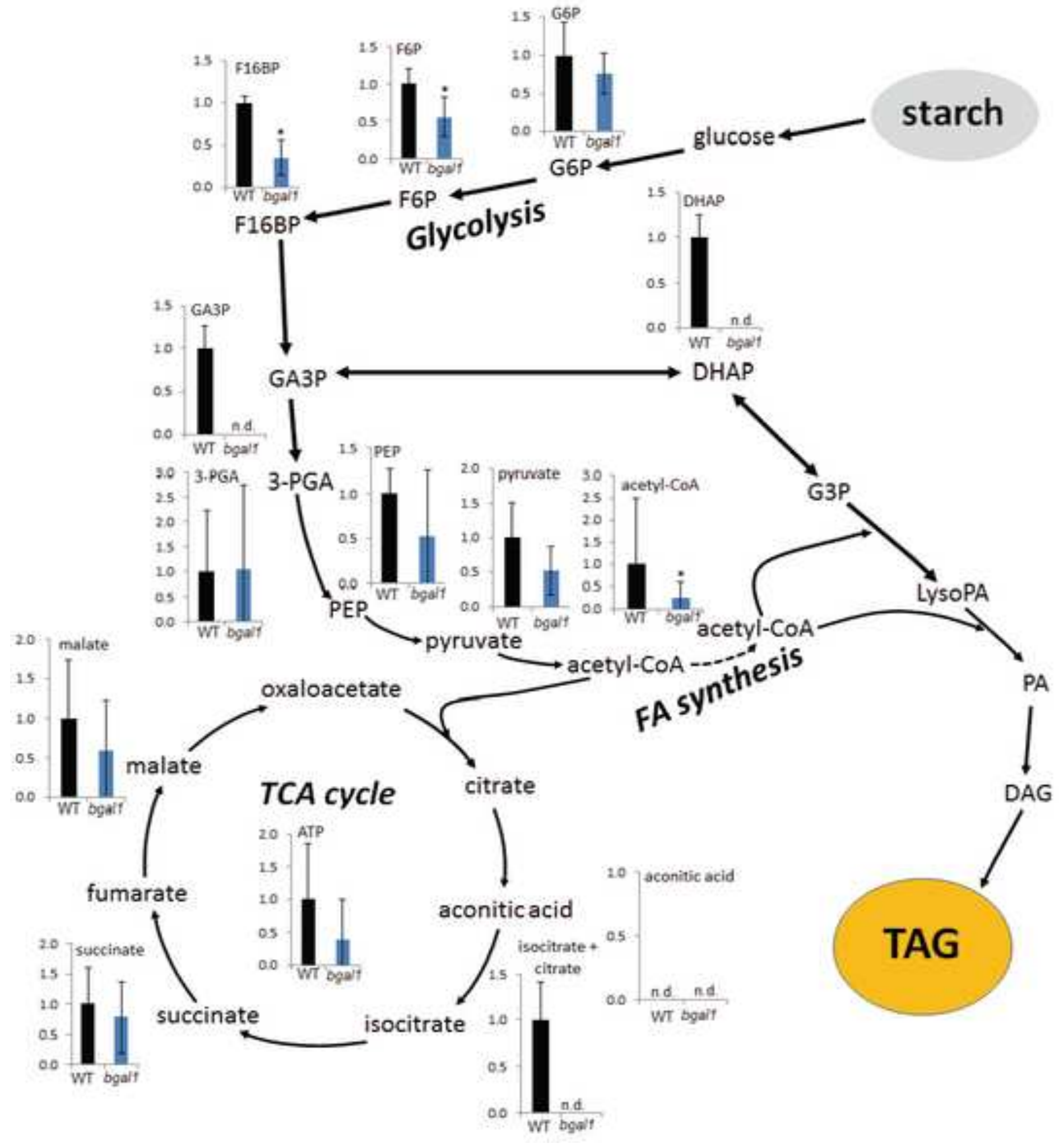

Figure $\epsilon$

TAG

\section{starch}

LysoPA 


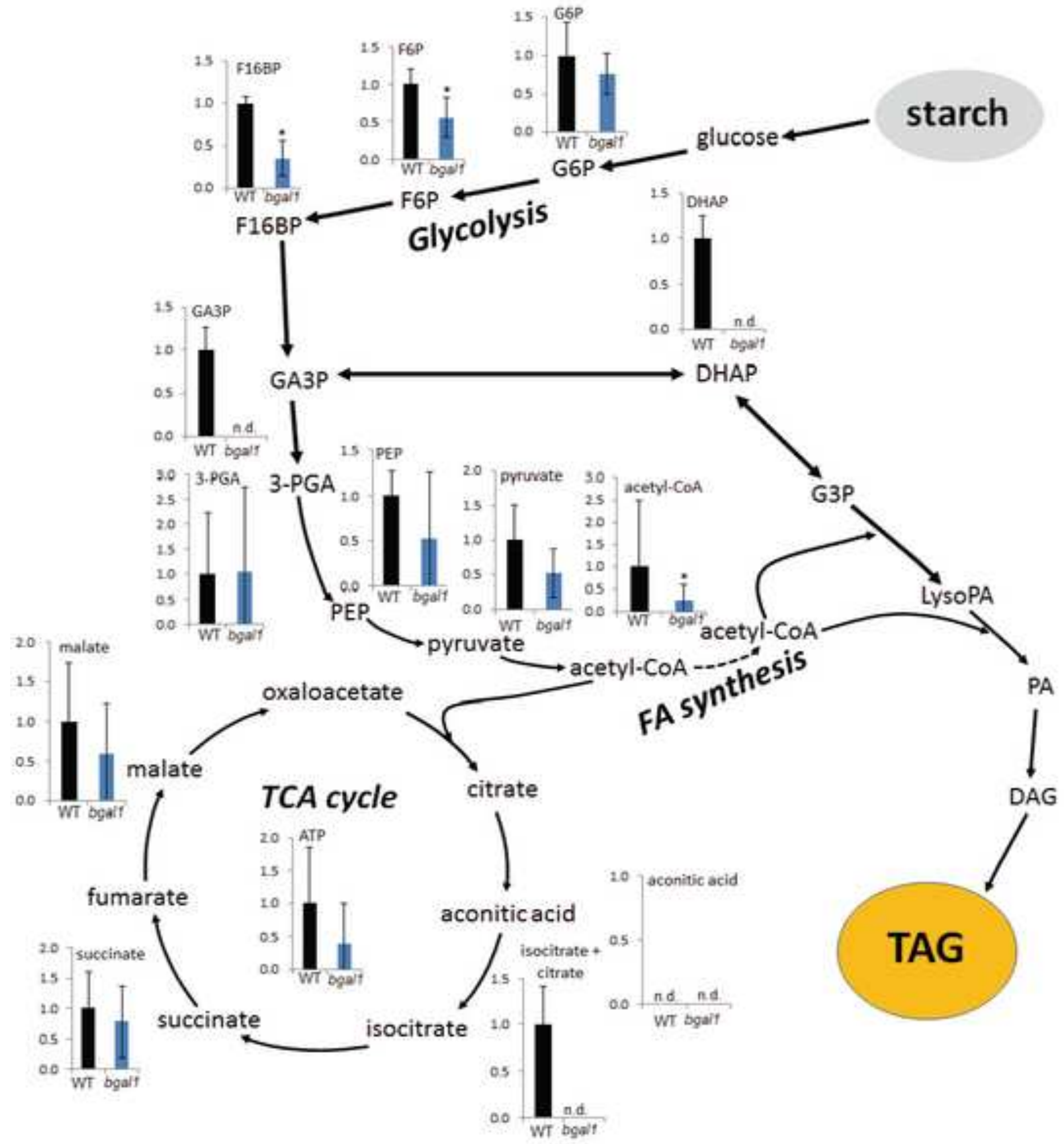

Figure 7

TAG

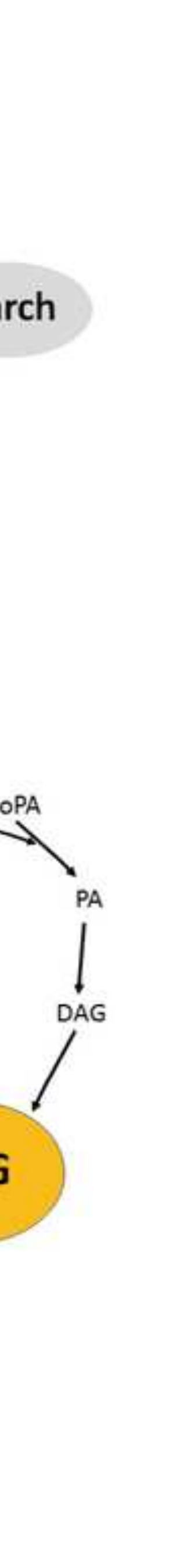

